ARTICLE

\title{
Mechanisms of telomerase inhibition by oxidized and therapeutic dNTPs
}

\author{
Samantha L. Sanford ${ }^{1}$, Griffin A. Welfer ${ }^{2}$, Bret D. Freudenthal (1D ${ }^{2}$ \& Patricia L. Opresko (1) 1,3凶
}

Telomerase is a specialized reverse transcriptase that adds GGTTAG repeats to chromosome ends and is upregulated in most human cancers to enable limitless proliferation. Here, we uncover two distinct mechanisms by which naturally occurring oxidized dNTPs and therapeutic dNTPs inhibit telomerase-mediated telomere elongation. We conduct a series of direct telomerase extension assays in the presence of modified dNTPs on various telomeric substrates. We provide direct evidence that telomerase can add the nucleotide reverse transcriptase inhibitors ddITP and AZT-TP to the telomeric end, causing chain termination. In contrast, telomerase continues elongation after inserting oxidized 2-OH-dATP or therapeutic 6-thio-dGTP, but insertion disrupts translocation and inhibits further repeat addition. Kinetics reveal that telomerase poorly selects against 6-thio-dGTP, inserting with similar catalytic efficiency as dGTP. Furthermore, telomerase processivity factor POT1-TPP1 fails to restore processive elongation in the presence of inhibitory dNTPs. These findings reveal mechanisms for targeting telomerase with modified dNTPs in cancer therapy.

\footnotetext{
${ }^{1}$ Department of Environmental and Occupational Health, University of Pittsburgh Graduate School of Public Health and UPMC Hillman Cancer Center, Pittsburgh, PA, USA. ${ }^{2}$ Department of Biochemistry and Molecular Biology, University of Kansas Medical Center, Kansas City, KS, USA. ${ }^{3}$ Center for Nucleic Acids Science and Technology, Carnegie Mellon University, Pittsburgh, PA, USA. ${ }^{\circledR}$ email: plo4@pitt.edu
} 
T elomeres cap linear chromosome ends, and in humans it consist of GGTTAG repeats and a protective protein complex called shelterin ${ }^{1}$. Critically short telomeres trigger a DNA damage response and cell senescence which contribute to aging-related diseases ${ }^{2}$. Telomeres shorten during each replication due to the end replication problem ${ }^{3}$. The ribonucleoprotein complex, telomerase, counteracts this problem by adding telomeric repeats to chromosome ends ${ }^{4}$. Human telomerase consists of two main components, a reverse transcriptase (TERT) and a functional RNA (TR) which contains the template sequence for synthesis of GGTTAG repeats ${ }^{5}$. Telomerase is expressed in human germ and stem cells, and is upregulated in over $85 \%$ of cancers, enabling unlimited proliferation and tumorigenesis ${ }^{6,7}$. Therefore, inhibiting telomerase activity is a promising therapeutic strategy to treat many cancers.

Numerous studies show that oxidative stress causes accelerated telomere shortening 8 . Oxidative stress is an imbalance between reactive oxygen species (ROS) and antioxidant defense systems in the cell. ROS are highly reactive toward biomolecules and cellular components including lipids, proteins, and nucleic acids. Free deoxynucleotide triphosphates (dNTPs) are highly susceptible to oxidative damage from ROS, and insertion of oxidized dNTPs into the genome by DNA polymerases during replication or repair is mutagenic and toxic to cells ${ }^{9,10}$. To prevent this, MutT homolog 1 (MTH1) hydrolyzes oxidized dNTPs (e.g. 8-oxodGTP, 2-OH-dATP, and 8-oxo-dATP) (Fig. 1a), and is a target for cancer therapy since cancer cells are thought to have higher levels of oxidized dNTPs and are more sensitive to MTH1 inhibition $^{10,11}$. MTH1 depletion inhibits telomere maintenance and telomerase activity in cancer cells under oxidative stress conditions, and telomerase insertion of 8-oxo-dGTP terminates further telomere elongation in vitro ${ }^{12-14}$. However, MTH1 also removes oxidized dATPs, but whether these damaged nucleotides can inhibit telomerase, similar to 8-oxo-dGTP, and contribute to telomere shortening is unknown.

While oxidized dNTPs arise naturally, synthetic modified dNTPs and nucleoside analogs have a long history of successful use for anti-viral and cancer therapies. Nucleoside reverse transcriptase inhibitors (NRTIs) block human immunodeficiency virus (HIV) reverse transcriptase (RT) to prevent viral replication. In their phosphorylated form, NRTIs compete with natural dNTPs for insertion by HIV-1 RT, and act as chain terminators ${ }^{15}$. The catalytic core of TERT is structurally homologous to the HIV-1 RT domain ${ }^{16}$, and telomerase inhibition has been proposed to contribute to premature aging observed in HIV patients undergoing long-term NRTI therapy ${ }^{17,18}$. While studies confirmed that various NRTIs cause telomere shortening and inhibit telomerase in vitro ${ }^{19-21}$, whether telomerase can insert these
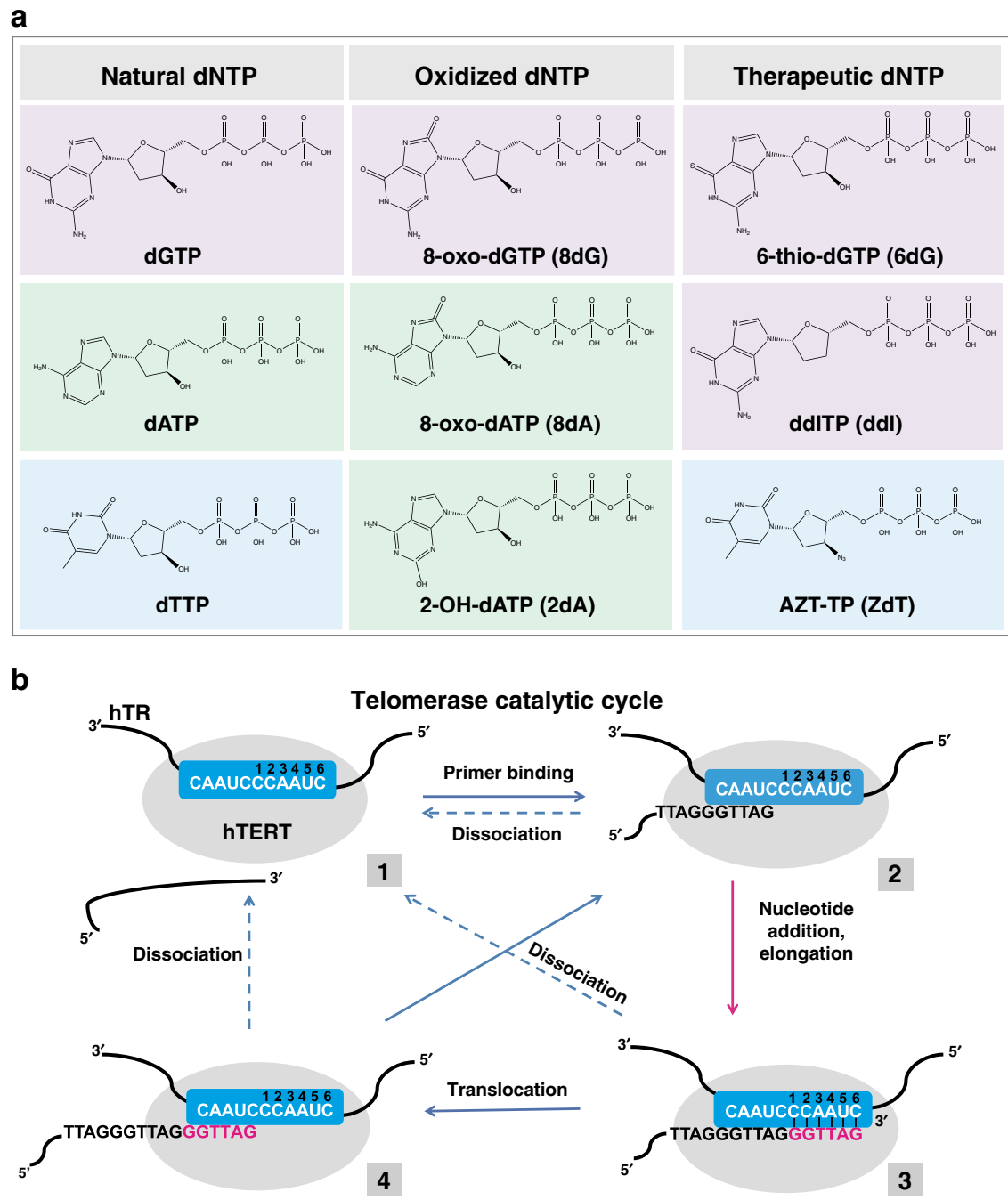

Fig. 1 dNTPs used in telomerase reactions. a Chemical structures of dNTP analogs used in this study and the corresponding natural dNTP shown in the same color. b Telomerase catalytic cycle. Blue indicates the telomerase RNA template; black indicates DNA primer; red indicates newly added nucleotides; numbers represent the steps in the cycle. 
chain-terminating analogs during telomere synthesis was unknown. Thiopurines are another class of therapeutic nucleoside analogs that cause telomere shortening, and are currently used in clinical practice as antileukemic, anti-inflammatory, and immunosuppressive agents ${ }^{22-24}$. 6-thio-dGTP, which forms in cells from 6-thio-dG, promotes cell death in telomerase-positive cancer cells but not in normal cells, and decreases tumor growth in mouse xenograft studies ${ }^{25}$. While 6-thio-dG causes telomere shortening and dysfunction, the mechanism is unclear because extracts from treated cells do not show reduced telomerase activity $^{25}$. Furthermore, since both NRTIs and thiopurines can elevate ROS by causing mitochondrial dysfunction, they may increase oxidative damage within nucleotide pools ${ }^{26,27}$.

Here, we systematically investigate how oxidized dATPs (2OH-dATP and 8-oxo-dATP) and synthetic therapeutic dNTPs (derived from 6-thio-dG, didanosine (ddITP), and azidothymidine (AZT-TP)) (Fig. 1a) impact telomerase activity, to determine how these modified dNTPs drive telomere shortening and dysfunction. We conduct a series of direct telomerase extension assays in the presence of modified dNTPs on various telomeric substrates to define mechanisms of inhibition. We find that oxidized dATPs also inhibit telomerase activity, but unlike 8-oxodGTP, 2-OH-dATP is not mutagenic or a chain terminator. Rather, our data indicate 2-OH-dATP impedes telomerase translocation and further nucleotide and repeat addition. 6-thiodGTP strongly inhibits telomerase by disrupting translocation, similar to 2-OH-dATP. Finally, we demonstrate that telomerase inserts NRTIs ddITP and AZT-TP during DNA synthesis, and that these analogs are genuine chain terminators. Cumulatively, we uncover two distinct mechanisms by which oxidized and therapeutic dNTPs promote telomere shortening.

\section{Results}

Modified dNTPs decrease telomerase processivity. To determine if telomerase can utilize oxidatively damaged 2-OH-dATP and 8-oxo-dATP or therapeutic NRTIs and 6-thio-dGTP (Fig. 1a) for telomere elongation, we conducted direct repeat addition assays. For NRTIs, we selected ddITP and AZT-TP based on evidence they promote telomere shortening ${ }^{20,21,28}$. The telomerase catalytic cycle starts when the telomeric single strand overhang base pairs with the complementary $3^{\prime}$ end of the telomerase RNA template priming synthesis ${ }^{5}$. Upon incorporation of the incoming dNTP, the telomerase active site moves to the next template base and telomere elongation continues until the template $5^{\prime}$ boundary is reached for processive nucleotide addition (Fig. 1b, steps 2 and 3). In human telomerase, the template region is $11 \mathrm{nt}\left(3^{\prime}\right.$-rCAAUCCCAAUC- $\left.5^{\prime}\right)$ comprising of an alignment region plus a template sequence (numbered 1-6 in Fig. 1b). Then, telomerase can either dissociate or translocate on the DNA product, generating a realigned 5-bp RNA:DNA hybrid for processive repeat addition. The 6-nt RNA template is reverse transcribed for each cycle of repeat addition and template recycling (Fig. 1b, steps 2-4). Nucleotide addition processivity (NAP) is the number of nucleotides added prior to enzyme dissociation from the template, and repeat addition processivity (RAP) is the number of repeats added prior to dissociation.

For telomerase reactions, we used the standard substrate of three TTAGGG repeats and immunopurified FLAG-tagged telomerase overexpressed in human HEK 293T cells. This preparation, termed super telomerase, has kinetic properties similar to endogenous

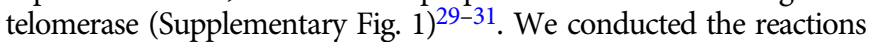
with cellular relevant dNTP concentrations $(24 \mu \mathrm{M}$ dATP, $29 \mu \mathrm{M}$ dCTP, $37 \mu \mathrm{M}$ dTTP, $5.2 \mu \mathrm{M}$ dGTP, averaged from multiple studies $^{32}$ ), since dNTP pool balance can impact DNA synthesis ${ }^{32}$. We replaced increasing concentrations of the natural dNTP with the corresponding oxidized or therapeutic dNTP analog $(0.5-125 \mu \mathrm{M})$ in reactions containing the remaining three natural dNTPs. Repeat processivity was measured using the convention of calculating the number of repeats synthesized before half of the DNA substrates dissociate from telomerase ${ }^{33}$ (Supplementary Fig. 2). 8-oxo-dGTP served as a control since it is an established telomerase chain terminator $^{12}$. Increasing dGTP, dATP, or dTTP greatly increased repeat processivity as evidenced by the appearance of longer products (Fig. 2). Loss of signal at the highest dGTP concentration was due to dGTP outcompeting the low radioactive dTTP amounts used to label products, and was not observed in dATP or dTTP titration reactions containing radio-labeled dGTP (Fig. 2 and Supplementary Fig. 2). Similar to 8-oxo-dGTP, 8-oxo-dATP failed to support processive repeat addition (Fig. 2a, b). In contrast, we observed moderate telomeric synthesis in the presence of 2-OH-dATP, but repeat processivity was lower than reactions with unmodified dATP (Fig. 2b and Supplementary Fig. 2). These data indicate that oxidatively damaged dATPs inhibit telomerase, although to a different extent depending on the modification.

Next, we examined whether telomerase could utilize therapeutic dNTPs for elongation. Reactions with 6-thio-dGTP showed only one repeat added, although at the highest 6-thio-dGTP concentrations, telomerase incorporated two additional nucleotides after translocation at the $\mathrm{rC}_{1} \mathrm{rC}_{2}$ positions (Fig. $2 \mathrm{a}$, lanes 7 and 8). This suggests 6-thio-dGTP inhibits both nucleotide and repeat processivity. Although the NRTI didanosine is an adenine analog, it is converted to either ddATP or ddITP, which is an isoguanine ${ }^{34,35}$. When ddITP replaced dGTP in the reaction, we observed no synthesis past the first $\mathrm{rC}_{6}$ template even with increasing ddITP concentrations (Fig. 2a, lanes 9 and 10). Virtually no products were observed in reactions containing AZT-TP, although incorporation opposite the first $\mathrm{rA}_{3}$ template blocks further extension (Fig. 2c). In summary, the aborted extension products show substitution of the natural dNTPs with 8-oxo-dNTPs inhibit telomerase to a similar extent as substitution with HIV-RT chain terminators or 6-thio-dGTP. Our data suggest that either telomerase cannot incorporate these modified dNTPs during telomeric DNA synthesis, or following incorporation, they inhibit further elongation of the telomere.

Telomerase inhibition mechanism depends on the modified dNTP. A chain terminating mechanism of inhibition requires that the enzyme adds the modified dNTP to a growing chain, which then blocks further synthesis. Since we showed previously that 8 oxo-dGTP is a telomerase chain terminator, we used it as a positive control $^{12}$. To test whether telomerase can incorporate other modified dNTPs, and whether the incorporation is chain terminating and/or mutagenic, we conducted direct extension assays in which we radiolabeled the primer and added increasing concentrations (5, 50 , and $500 \mu \mathrm{M}$ ) of a single dNTP (Supplementary Figs. 3, 5, 6, and 7). Since modified dNTPs may prefer mispairing, we tested various primers in which the first template base was either $\mathrm{rA}_{3}, \mathrm{rC}_{1}$, or $\mathrm{rU}_{5}$ (primer 1, primer 2, and primer 3, respectively), and compared the percent primer extension for each dNTP at the middle $50 \mu \mathrm{M}$ concentration (Fig. 3). Primers 1 and 2 initiate synthesis at consecutive $\mathrm{rA}_{3} \mathrm{rA}_{4}$ or $\mathrm{rC}_{1} \mathrm{rC}_{2}$ template bases, respectively, so we could examine both incorporation and extension to the next base. However, the telomerase template lacks tandem $\mathrm{rU}$ residues.

We first tested incorporation of natural dNTPs at the various template positions as controls. Reactions with a single dNTP type is an established method for determining DNA synthesis fidelity, defined as selectivity for incorporating a correct dNTP versus an incorrect or modified dNTP 36,37 . Interestingly, telomerase extended all three primers in the presence of dGTP, suggesting telomerase may incorporate dGTP opposite each template base even at low cellular 
a
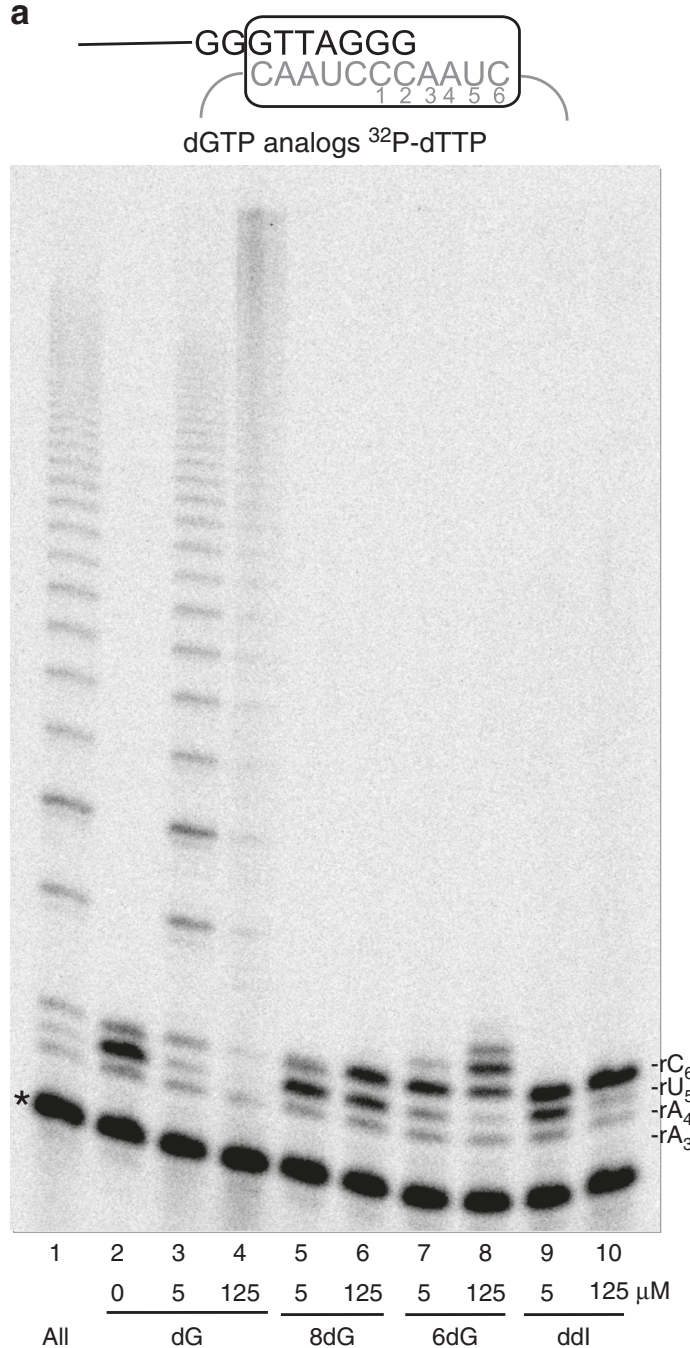

b

C
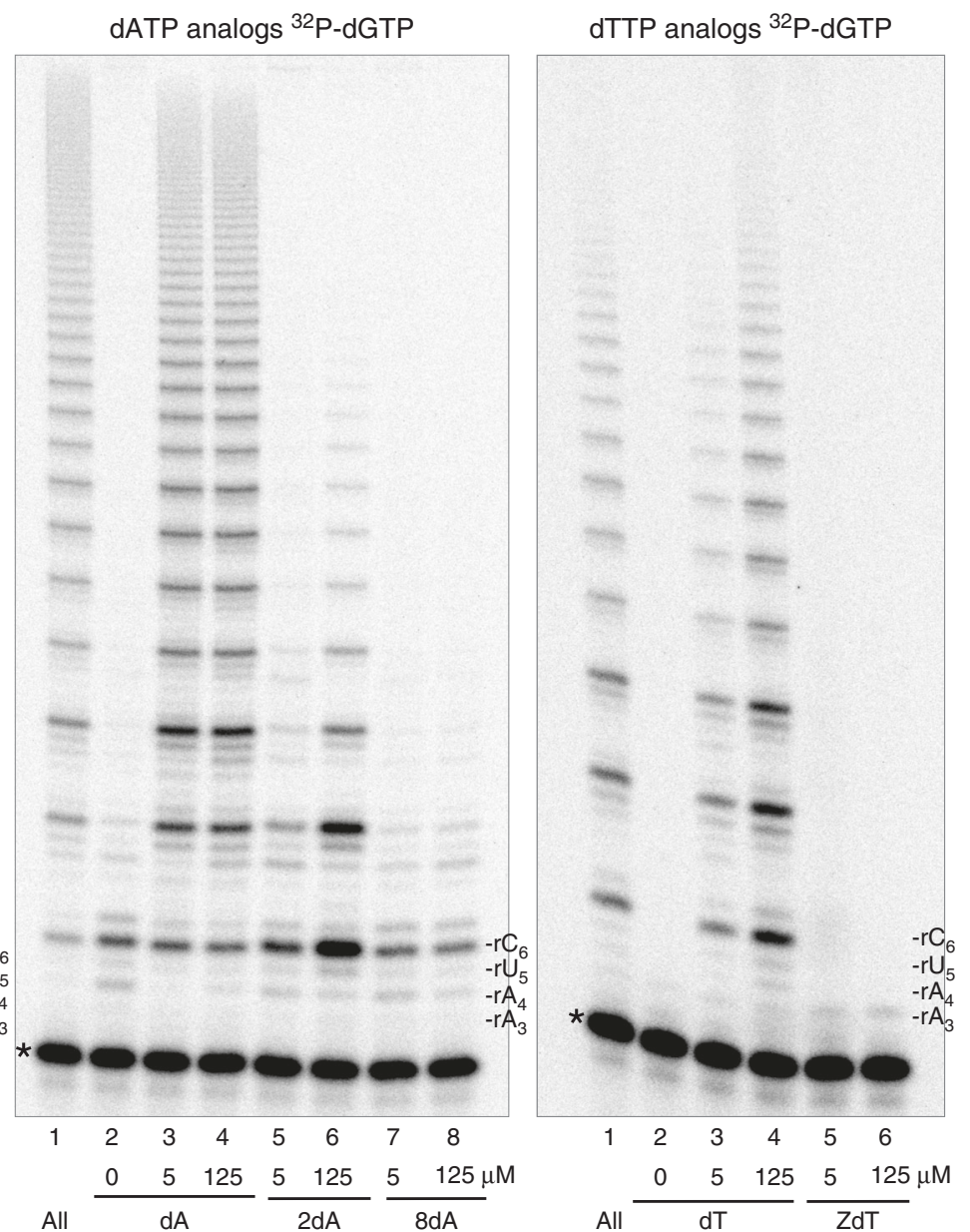

Fig. 2 Oxidized and therapeutic dNTPs inhibit telomerase processivity. Telomerase reactions were conducted with (TTAGGG) 3 primer and cellularconcentration dNTPs except that the indicated natural or modified dNTP was titrated in at increasing concentrations $(0,5,125 \mu \mathrm{M})$ along with either $0.3 \mu \mathrm{M}\left[\alpha^{-32} \mathrm{P}\right] \mathrm{dTTP}$ a or $0.3 \mu \mathrm{M}\left[\alpha^{-32} \mathrm{P}\right] \mathrm{dGTP} \mathbf{b}, \mathbf{c}$ to label the products. The loading control $\left(^{\star}\right)$ was a $32 \mathrm{P}$-end labeled 18 -mer oligonucleotide. Numbers on the left indicate the number of added repeats; letters on the right indicate template residue. Images are representative of three independent experiments.

concentrations $(5 \mu \mathrm{M})$ (Supplementary Fig. 3). However, comparisons at $50 \mu \mathrm{M}$ dGTP indicates a preference for correct incorporation over misincorporation in order of $\mathrm{rC}_{1}(33 \%$, primer 2$)>\mathrm{rA}_{3}(19 \%$, primer 1$)>\mathrm{rU}_{5}$ (4\%, primer 3 ) extension (Fig. 3 lanes 2$)$. We also observed telomerase synthesis of poly-dG ladders, as reported previously ${ }^{12}$, even at early time points and at a single $\mathrm{rC}$ (Supplementary Fig. 4a, b). As a control, reactions with DNA polymerase $\beta$ showed no evidence of dGTP laddering or misincorporation opposite template A (Supplementary Fig. 4c, d). Poly-nucleotide ladders were not observed in reactions with any other dNTP (Fig. 3) or with RNase addition (Supplementary Fig. 3d). In the presence of dTTP, telomerase preferentially extended primer 1 showing incorporation opposite $\mathrm{rA}_{3}$ and strong termination after $\mathrm{rA}_{4}$, as expected, but also minor extension to the subsequent $\mathrm{rU}_{5}$ (Fig. 3a lane 3, and Supplementary Fig. 5). Consistent with this, telomerase could extend primer 3 by misincorporating dTTP opposite $\mathrm{rU}_{5}$ (Fig. $3 \mathrm{c}$ lane 3). Thus, while telomerase can misinsert dTTP, it strongly prefers correct insertion (41\% primer 1 extension versus $9 \%$ primer 3 extension). Similarly, telomerase strongly preferred correct insertion of dATP opposite $\mathrm{rU}_{5}$, elongating primer 3 with minimal extension to the next $\mathrm{rC}_{1}$, and poor or no extension of primers 1 and 2, respectively (Fig. 3 lane 4). Finally, telomerase only extended primer 1 in the presence of dCTP, indicating some misincorporation opposite $\mathrm{rA}_{3}$ (Fig. 3 lane 5, Supplementary Fig. 5). In summary, telomerase extension was most accurate with primer 2 (template $\mathrm{rC}_{1}$ ) and least accurate with primer 1 (template $\mathrm{rA}_{3}$ ). Additionally, telomerase incorporation of dGTP is more error prone than the other natural dNTPs, as indicated by the production of poly $\mathrm{d}(\mathrm{G})$ ladders.

We next tested whether telomerase can incorporate oxidized dATPs onto the growing telomere chain using the end-labeled primers. Telomerase elongated primer 1 by misinserting 8-oxodGTP opposite $\mathrm{rA}_{3}$ with minimal extension to the next template $\mathrm{rA}_{4}$, confirming its chain-terminating ability (Fig. 3 lane 6 and Supplementary Fig. 6$)^{12}$. Telomerase showed little to no extension of primers 2 and 3 with 8-oxo-dGTP, indicating poor incorporation opposite $\mathrm{rC}_{1}$ or $\mathrm{rU}_{5}$. In contrast, we detected virtually no extension of any primers with 8-oxo-dATP, except for minimal misinsertion opposite $\mathrm{rA}_{3}$ with primer 1 (Fig. 3 lane 7 and Supplementary Fig. 6), suggesting 8-oxo-dATP is a very poor substrate for telomerase. However, telomerase readily extended primer 3 by inserting 2-OHdATP opposite the correct $\mathrm{rU}_{5}$, generating only 2 -fold less product than with dATP ( $16 \%$ versus $30 \%$, respectively), and showed minimal extension to the next incorrect $\mathrm{rC}_{1}$ position (Fig. 3 lane 8). 


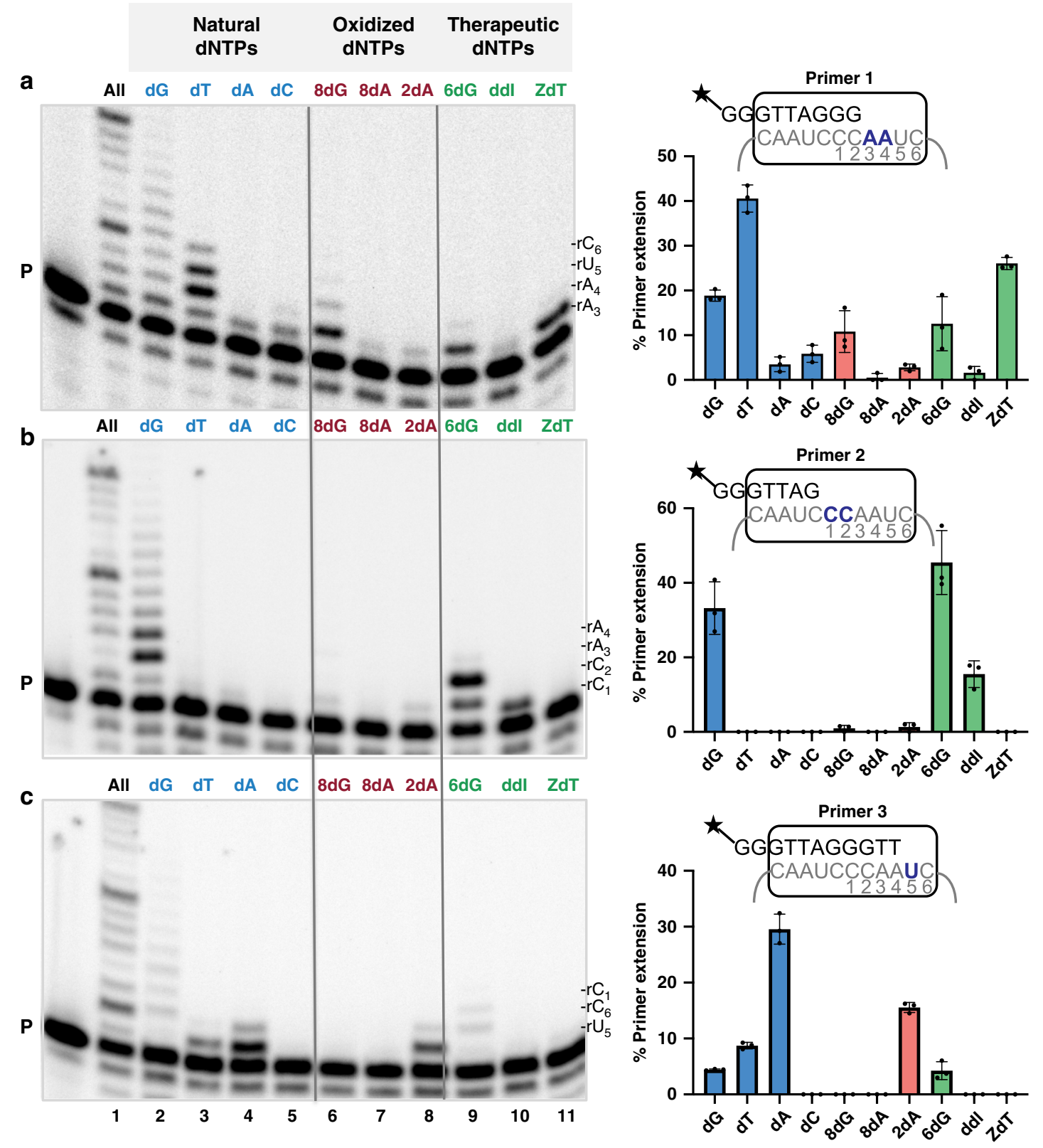

Fig. 3 Telomerase insertion of modified dNTPs. Telomerase reactions were conducted with $5 \mathrm{nM}$ 32P-end labeled primer a Primer 1 (TTAGGG), $\mathbf{b}$ Primer 2 (GGTTAG) 3 , or c Primer 3 (AGGGTT) 3 . Reactions contained cellular-concentration dNTPs (lane 1) or $50 \mu \mathrm{M}$ of indicated natural dNTP (blue, lanes 2-5), oxidized dNTP (red, lanes 6-8), or therapeutic dNTP (green, lanes 9-11). Products were separated on denaturing gels. 8dG (8-oxo-dGTP); 8dA (8-oxodATP); 2dA (2-OH-dATP); 6dG (6-thio-dGTP); ddl (ddITP); ZdT (AZT-TP). Letters on the right indicate the template base; $P$ indicates unextended 18-mer primer. Graphs represent the percent of total primers extended. Images are representative of, and data are shown as mean $\pm \mathrm{s}$.d. from, three independent experiments. Source data are provided as a Source Data file.

Unlike 8-oxo-dGTP, telomerase insertion of 2-OH-dATP is not mutagenic, showing very low extension of primers 1 and 2 indicative of poor misinsertion opposite $\mathrm{rA}_{3}$ and $\mathrm{rC}_{1}$, respectively. The single template $\mathrm{rU}$ did not allow us to determine whether 2$\mathrm{OH}$-dATP insertion is chain terminating. In summary, our data indicate telomerase insertion of oxidized dNTPs follows the order 2-OH-dATP > 8-oxo-dGTP > 8-oxo-dATP opposite their preferred template base.

Analysis of the therapeutic dNTPs demonstrates that telomerase can add each of these analogs to a telomere chain. Regarding the NRTIs, telomerase inserted ddITP opposite $\mathrm{rC}_{1}$, extending primer 2 with moderate efficiency ( $16 \%$ extension) compared to reactions with dGTP (33\% extension), but did not extend to the next $\mathrm{rC}_{2}$ (Fig. 3 lane 10 and Supplementary Fig. 7). Telomerase extended primer 1 with AZT-TP, showing correct insertion opposite $\mathrm{rA}_{3}$ with no extension to the next $\mathrm{rA}_{4}$; yielding $26 \%$ extension compared to $41 \%$ extension with dTTP (Fig. 3 lane 11). These data definitively show that these HIV-1 RT chain terminators are also genuine telomerase chain terminators, and define the inhibition mechanism. Strikingly, telomerase was able to extend all three primers with 6-thio-dGTP, showing a preference for incorporation in order of template $\mathrm{rC}_{1}(45 \%)>$ $\mathrm{rA}_{3}(13 \%)>\mathrm{rU}_{6}(4 \%)$ primer extension (Fig. 3 lane 9), at product yields comparable to dGTP incorporation. In reactions with primer 2, telomerase correctly incorporated 6-thio-dGTP opposite $\mathrm{rC}_{1}$, showing strong termination after insertion opposite the next $\mathrm{rC}_{2}$. This suggests that, like dGTP, 6-thio-dGTP can bind at the telomerase active site at all template primer positions, 


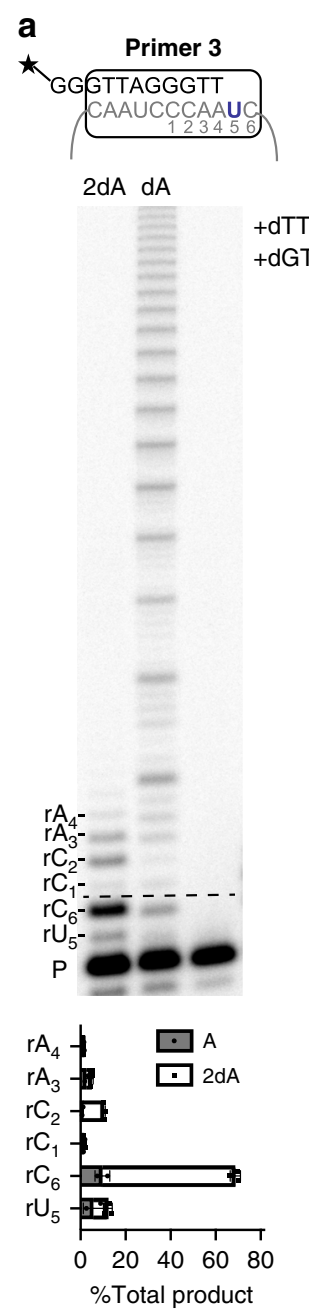

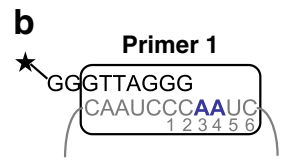
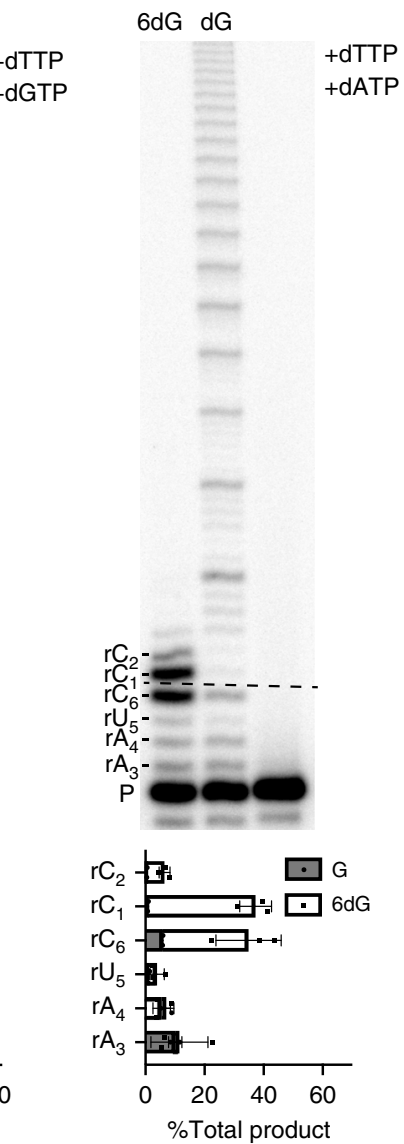

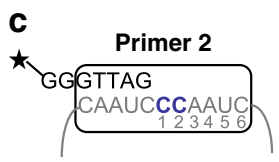

$6 \mathrm{dG} \quad \mathrm{dG}$

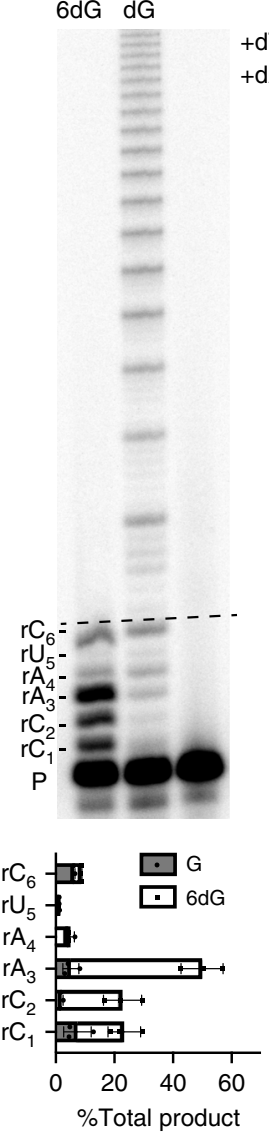

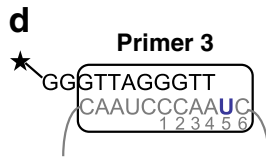

$6 d G d G$

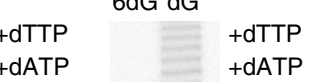

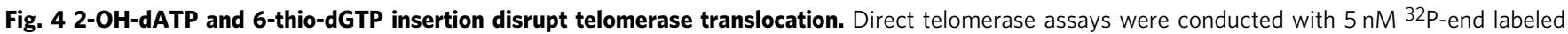
primer a and d Primer 3 (AGGGTT) ${ }_{3}$, b Primer 1 (TTAGGG) ${ }_{3}$, or c Primer 2 (AGGGTT) 3 . Reactions contained $50 \mu \mathrm{M}$ dATP, dTTP, and dGTP, except when 2-OH-dATP (2dA) or 6-thio-dGTP (6dG) was substituted for dATP or dGTP, respectively, where indicated. Products were separated on denaturing gels. Letters on the $y$-axis of the graph indicate the template base; $P$ indicates unextended 18-mer primer. Graphs represent percent of product terminated at each template position as a function of total products. Images are representative of, and data are the mean $\pm \mathrm{s}$.d. from, three independent experiments. Source data are provided as a Source Date file.

however unlike dGTP, it does not support poly-nucleotide laddering. Our data indicate telomerase insertion of therapeutic dNTPs follows the order 6-thio-dGTP $>$ AZT-TP $>$ ddITP. Unlike the NRTIs and 8-oxo-dGTP, 6-thio-dGTP is not a telomerase chain terminator, indicating the mechanism of inhibition is distinct.

2-OH-dATP and 6-thio-dGTP insertion disrupt translocation. To better understand how 2-OH-dATP and 6-thio-dGTP inhibit the telomerase catalytic cycle, we examined whether telomerase could incorporate a natural dNTP after adding the modified dNTP. First, we used primer 3 to examine extension after insertion opposite $\mathrm{rU}_{5}$ in reactions with $50 \mu \mathrm{M}$ each of dTTP, dGTP, and either dATP or 2-OH-dATP. We observed typical processive synthesis with all three natural dNTPs, but replacing dATP with 2-OH-dATP generated a strong termination product after extension to the next base $\left(\mathrm{rC}_{6}\right)$, which is the final base prior to translocation (Fig. 4a). These data indicate that telomerase can extend after insertion of 2-OH-dATP, but translocation to add the next repeat is greatly compromised. Those few reactions that continued after translocation terminated prior to reaching the template end, suggesting 2-OH-dATP disrupts both repeat and nucleotide processivity. Next, we conducted reactions with $50 \mu \mathrm{M}$ each of dATP, dTTP, and either dGTP or 6-thio-dGTP. Figure $4 \mathrm{~b}-\mathrm{d}$ show typical processive synthesis with the natural dNTP after initiating synthesis opposite $\mathrm{rA}_{3}$ (primer 1 ), $\mathrm{rC}_{1}$ (primer 2), and $\mathrm{rU}_{5}$ (primer 3). Next we replaced dGTP with 6thio-dGTP. Primer 1 reactions show strong termination products after telomerase inserted 6-thio-dGTP opposite $\mathrm{rC}_{6}$ position (4 nucleotides added) (Fig. 4b), suggesting dissociation prior to translocation. We also observed strong termination products at the next $\mathrm{rC}_{1}$ (5 nucleotides added), indicating either successful translocation in some reactions followed by dissociation, or template slippage for an additional 6-thio-dGTP incorporation prior to translocation. This result was recapitulated with primer 3 . Figure $4 \mathrm{~d}$ shows that after telomerase inserted dATP opposite $\mathrm{rU}_{5}$, the majority of the reactions terminated after 6-thio-dGTP insertion opposite $\mathrm{rC}_{6}$ or the next $\mathrm{rC}_{1}$. Finally, reactions with primer 2 show that telomerase incorporates 6-thio-dGTP opposite the first two $\mathrm{rC}_{1} \mathrm{rC}_{2}$ positions, but primarily terminates synthesis after extension to $\mathrm{rA}_{3}$ (three nucleotides added) prior to translocation, despite the availability of natural dNTPs to add another repeat (Fig. 4c). Telomerase can also add a natural nucleotide (dTTP opposite $\mathrm{rA}_{3}$ ) after 6-thio-dGTP insertion, 
a

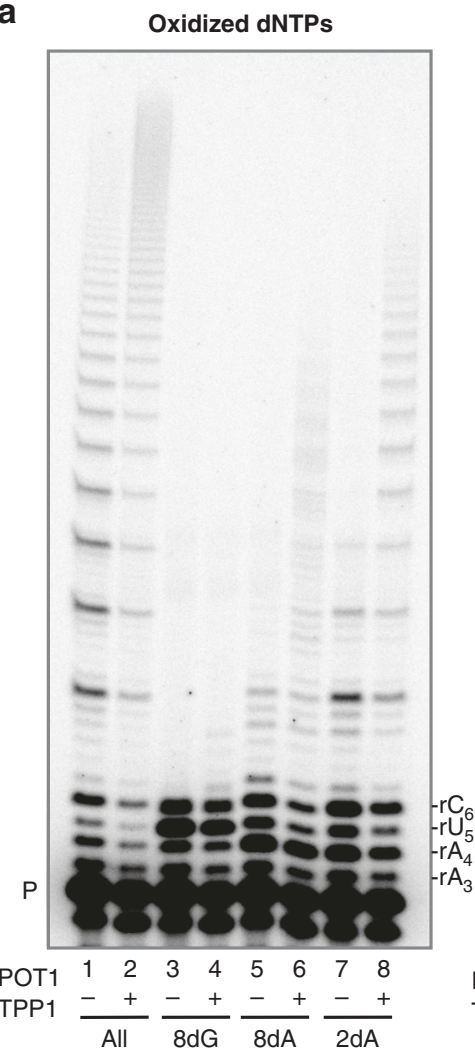

b
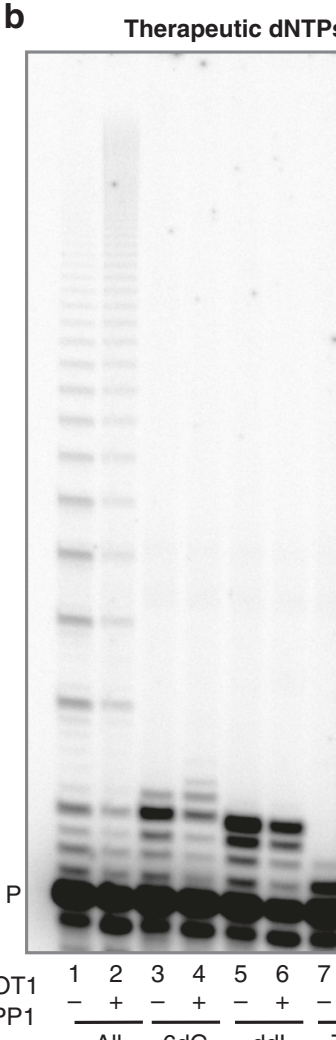

Therapeutic dNTPs

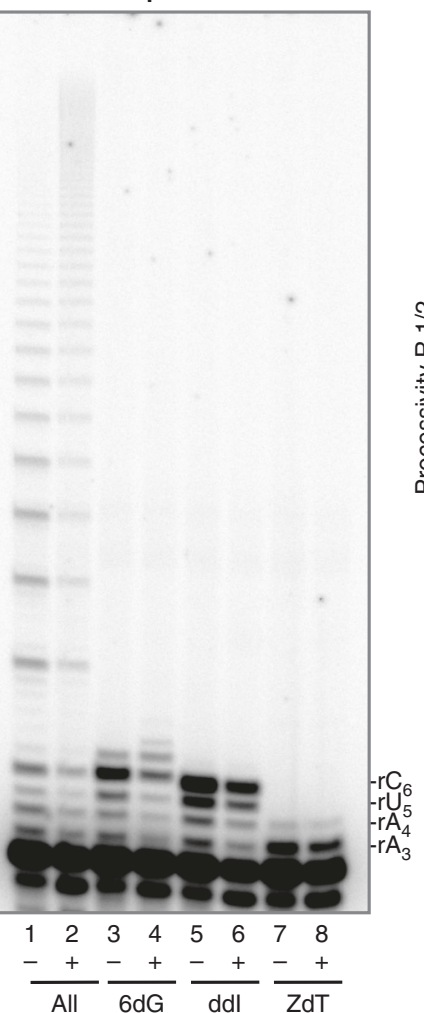

C
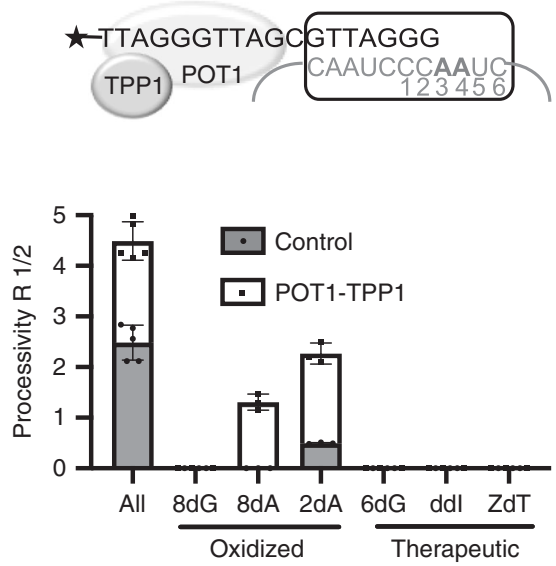

Fig. 5 POT1-TPP1 fail to overcome inhibitory dNTPs. Direct telomerase assays were conducted in the absence or presence of $500 \mathrm{nM} P O T 1$ and $500 \mathrm{nM}$ TPP1, as indicated, and $5 \mathrm{nM}$ 32P-end labeled primer (TTAGGGTTAGCGTTAGGG) designed to position POT1 at the 10 nt primer 5' end. Reactions contained cellular-concentration dNTPs (lanes 1 and 2), except when the natural dNTP was substituted with the oxidized dNTP a or therapeutic dNTP $\mathbf{b}$ analog (lanes 3-8), as indicated. 8dG (8-oxo-dGTP); 8dA (8-oxo-dATP); 2dA (2-OH-dATP); 6dG (6-thio-dGTP); ddI (ddITP); ZdT (AZT-TP). Letters on the right indicate template base; $\mathrm{P}$ indicates unextended 18-mer primer. $\mathbf{c}$ Processivity was calculated on the basis of total products normalized to loading control. Images are representative of, and data are shown as mean \pm s.d. from 3 to 5 independent experiments. Source data are provided as a Source Data file.

confirming 6-thio-dGTP is not a chain terminator. However, termination prior to completing synthesis of the 6-nt repeat indicates that 6-thio-dGTP not only disrupts repeat processivity, but also nucleotide processivity. Our data suggest 6-thio-dGTP and 2-OH-dATP addition interfere with telomerase processivity, and compromise translocation and further telomere extension.

POT1-TPP1 fail to rescue telomerase processivity inhibition. Next we tested whether the telomerase processivity factor POT1-TPP1 modulates modified dNTP inhibition of telomerase. POT1 binds to the telomeric ssDNA overhang, requiring the minimum sequence of $5^{\prime}$-TTAGGGTTAG-3/38. Inclusion of POT1-binding partner TPP1, increases the binding affinity for telomeric DNA ten-fold compared to POT1 alone ${ }^{39}$. POT1-TPP1 recruits telomerase to telomeres in vivo ${ }^{39}$, and greatly increases telomerase repeat processivity ${ }^{33}$. Therefore, we reasoned that POT1-TPP1 may overcome inhibition by the modified dNTPs and enhance telomerase processivity. We conducted telomerase extension reactions with radiolabeled primer in the presence of POT1-TPP1, and used a primer with a single mutation (TTAGGGTTAGCGTTAGGG; underlined G to C mutation) ${ }^{40}$ to ensure POT1-TP $\bar{P} 1$ is positioned at the $5^{\prime}$ portion of the primer (Fig. 5). This provides a homogenous substrate for telomerase extension.

For these reactions, we replaced the natural dNTP with the modified dNTP analog, while the other dNTPs remained at cellular relevant concentrations. As a positive control, we show the addition of POT1-TPP1 to telomerase reactions containing all natural dNTPs significantly increased repeat processivity $\left(R_{1 / 2}\right)$ from 2.5 to 4.5 , as indicated by the appearance of longer products (Fig. 5a lanes 1 and 2 , and $5 \mathrm{c}$ ). $R_{1 / 2}$ represents the number of repeats added before half of the DNA substrates dissociate from telomerase, meaning nearly half of the bound primers were elongated by roughly five repeats in the presence of POT1-TPP1. When dGTP was replaced with 8-oxo-dGTP, addition of POT1-TPP1 was unable to overcome the chain termination (Fig. 5a lanes 3 and 4). In contrast, for reactions in which 2-OHdATP replaced dATP, POT1-TPP1 enhanced repeat processivity 5 -fold from 0.5 to 2.3 (Fig. 5a lanes 7 and 8 , and 5 c). This suggests that $2-\mathrm{OH}-\mathrm{dATP}$ incorporation may reduce processivity by disrupting telomerase interaction with the primer, which may be partly compensated for by POT1-TPP1. For reactions in which dATP was replaced with 8-oxo-dATP, we observed some POT1-TPP1 stimulation, although elongation was still greatly reduced compared to control reactions (Fig. 5a lanes 5 and 6). However, we suspect this synthesis resulted from misincorporation of dGTP or dTTP opposite $\mathrm{rU}_{5}$ in the absence of dATP (Fig. 3c lanes 2 and 3), since 8 -oxo-dATP is a poor telomerase substrate. As expected, POT1-TPP1 failed to stimulate telomerase processivity in reactions containing ddITP and AZT-TP, since insertion of ddITP opposite $\mathrm{rC}_{6}$ and AZT-TP opposite $\mathrm{rA}_{3}$ halted further synthesis (Fig. 5b lanes 5-8). However, POT1-TPP1 also failed to stimulate telomerase when dGTP was replaced with 6thio-dGTP (Fig. 5b lanes 3 and 4), indicating this analog is also a strong telomerase inhibitor. Overall, these data indicate that 
POT1-TPP1 cannot fully restore telomerase extension in the presence of inhibitory dNTPs, although these proteins can partly stimulate processivity in reactions containing $2-\mathrm{OH}-\mathrm{dATP}$.

Poor selectivity against 6-thio-dGTP ddITP and 2-OH-dATP. In order to better understand the ability of modified dNTPs to compete with natural dNTPs for telomerase utilization, we added modified dNTPs to reactions containing all four natural dNTPs. We conducted reactions with cellular relevant concentrations of natural dNTPs and titrated the modified dNTP from 0 to 10,000 $\mu \mathrm{M}$ to calculate the half-maximal inhibitory concentration $\left(\mathrm{IC}_{50}\right)$ based on telomerase repeat processivity (Supplementary Figs. 8 and 9). The calculated $\mathrm{IC}_{50}$ determines the concentration required to reduce repeat processivity in the bulk reactions by half. However, it is important to note that bulk experiments cannot distinguish effects on individual telomeres, since extended telomeres mask unextended telomeres. Incorporation of a chain terminator during any step will terminate extension of the affected telomere, and just five critically short telomeres are sufficient to trigger senescence ${ }^{41}$. Therefore, repeat processivity $\mathrm{IC}_{50}$ values are not necessarily an indicator of the inhibitory potency, but provide information on selectivity for modified dNTPs compared to natural dNTPs. The oxidized dNTPs 8-oxo-dATP and 8-oxo-dGTP had similar $\mathrm{IC}_{50}$ values as the genuine chain terminator AZT-TP ranging from 402 to $1690 \mu \mathrm{M}$ (Table 1). However, the therapeutic dNTPs 6-thio-dGTP and ddITP, and oxidized 2-OH-dATP, displayed the lowest $\mathrm{IC}_{50}$ values of 5, 61, and $103 \mu \mathrm{M}$, respectively. Our data suggest these modified dNTPs, especially 6-thio-dGTP, can effectively compete with the natural dNTPs for binding in the telomerase active site. Given the remarkably low $\mathrm{IC}_{50}$ for 6 -thio-dGTP, we examined the catalytic efficiency of 6-thio-dGTP incorporation versus dGTP using the Tribolium castaneum (tcTERT) model of the telomerase catalytic core ${ }^{42}$. The ability to purify sufficient quantities of $t c$ TERT enables characterization of the catalytic nucleotide addition by pre-steady-state single turnover kinetics using a defined DNA-RNA primer-template substrate ${ }^{43}$. The catalytic efficiency of incorporating a single dNTP is measured by dividing the observed nucleotide incorporation rate constant, $k_{\text {pol }}$, by the equilibrium dissociation constant for dNTP binding to the $t c$ TERT-primer-template complex $\left(K_{\mathrm{d}}\right)^{44}$. The catalytic efficiency of inserting dGTP is only 2 -fold higher at $0.034 \mu \mathrm{M}^{-1} \mathrm{~s}^{-1}$ compared to 6-thio-dGTP at $0.056 \mu \mathrm{M}^{-1} \mathrm{~s}^{-1}$, indicating poor selectivity against this dNTP analog (Table 2). Collectively, these

\section{Table 1 Telomerase processivity $I_{50}$ values.}

\section{Modified dNTP}

8-oxo-dATP

2-OH-dATP

8-oxo-dGTP

ddITP

AZT-TP

6-thio-dGTP

$\mathrm{IC}_{50} \boldsymbol{\mu} \mathbf{M} \pm \mathrm{SD}$

$946 \pm 49$

$103 \pm 66$

$1690 \pm 172$

$61 \pm 23$

$402 \pm 169$

$5 \pm 2$ results indicate that modified dNTPs vary in the ability to compete with the natural dNTPs for utilization by telomerase.

\section{Discussion}

Treatments with NRTIs and thiopurines, or the failure to remove oxidized dNTPs, drive telomere shortening in human cells $^{12,13,21,25,28}$. Here, we report two distinct mechanisms by which oxidized and therapeutic dNTPs inhibit telomerasemediated telomere elongation, either by chain termination or by disrupting translocation and subsequent repeat addition. By using end labeled primers, we provide direct evidence that telomerase can add the HIV-1 RT inhibitors ddITP and AZT-TP to a growing telomere chain, and that incorporation halts further elongation. Unlike the NRTIs and 8-oxo-dGTP, we found that telomerase can continue elongation after inserting 2-OH-dATP and 6-thio-dGTP, but that addition of these modified dNTPs strongly inhibits repeat processivity and nucleotide processivity, leading to truncated products. We propose a mechanism by which insertion of these processivity inhibitors disrupt stable formation of the RNA:DNA hybrid required for successful translocation and continued repeat addition.

Defining the mechanism of telomerase inhibition requires analysis of whether telomerase can catalyze addition of the modified dNTP to the telomeric end. Reactions with a single dNTP type also inform about selectivity for inserting a correct dNTP versus an incorrect or modified dNTP during DNA synthesis ${ }^{44}$. Accuracy depends on discrimination against base pairs that cannot adopt Watson-Crick like geometry. Control reactions with natural dNTPs at different template positions revealed features of telomerase accuracy. We found that telomerase incorporation of dGTP is more error prone than the other natural dNTPs, as suggested by dGTP misincorporation at low $5 \mu \mathrm{M}$. This propensity for telomerase to misinsert dGTP can outcompete the radioactive dTTP used to label the products in Fig. 2a, explaining the loss of radiolabeled products at high dGTP. Some dTTP misincorporation opposite template $r U$ even at low $5 \mu \mathrm{M}$, likely explains the one repeat addition observed when dATP is absent in Fig. 2b. For reactions containing only dGTP, the poly-d $(G)$ ladders appeared at early time points and low percent primer extension $(<10 \%)$ suggesting they resulted from processive nucleotide addition. Previous reports proposed telomerase synthesis of poly-d(G) ladders is due to DNA hairpininduced slippage of the product $3^{\prime}$ end relative to the template $\mathrm{rC}$ tract ${ }^{6,45}$. Primer slippage may contribute to dGTP addition opposite non-rC residues, although poly- $\mathrm{d}(\mathrm{G})$ laddering is not observed at low $(5 \mu \mathrm{M}) \mathrm{dGTP}$, but there is misinsertion opposite rA. High dGTP concentrations can overcome the templateembedded pause site that slows addition of the first dGTP for GGTTAG repeat synthesis ${ }^{46}$. Telomerase has a lower $K_{\mathrm{m}}$ for dGTP incorporation than other dNTPs, which suggests that telomerase has increased dGTP-binding affinity $37,46-48$, and may explain the higher propensity for dGTP misinsertion and poly-d (G) synthesis. The lower physiological concentration of dGTP $(5 \mu \mathrm{M})$, relative to the other $\mathrm{dNTPs}^{32}$, likely minimizes dGTP misincorporation and laddering in vivo. Furthermore, accessory proteins may assist telomerase fidelity.

Table 2 Single-turnover kinetic values for tcTERT single nucleotide insertion.

\begin{tabular}{|c|c|c|c|c|}
\hline 6-thio-dGTP & $3.1 \pm 0.23$ & $92.4 \pm 12.94$ & $0.034 \pm 0.005$ & 0.579 \\
\hline
\end{tabular}


The oxidative stress-induced telomere shortening observed upon MTH1 inhibition has been attributed to telomerase 8oxodGTP insertion which prevents further elongation ${ }^{12,14}$. Our biochemical results indicate that oxidized dATPs can also contribute to telomerase inhibition in MTH1-depleted cells. Although 8-oxo-dATP is a very poor telomerase substrate, it inhibits processivity. Polymerase studies with 8 -oxo-dATP are lacking, but mammalian DNA polymerases insert dTTP or dGTP opposite a template 8-oxodA and accommodate the base pairs through base tautomerization and interactions with active site residues ${ }^{49}$. Telomerase may lack contacts required to stabilize an 8-oxodA base pair for catalysis, or 8-oxo-dATP may occupy the active site in a non-productive manner blocking natural dNTP access, similar to telomerase inhibitor 5-MeCITP ${ }^{50}$. In contrast, a 2-OH-dATP:rU base pair is well tolerated in the telomerase active site since 2-OH-dATP insertion opposite $\mathrm{rU}$ is only 2-fold less efficient than dATP. 2-OH-dATP can pair with thymine or uracil either in an enol tautomeric form with Watson-Crick hydrogen bonding, or in a keto form through wobble base pairing ${ }^{51,52}$. Similarly, HIV-1 and avian myeoblastosis virus RTs preferentially insert 2-OH-dATP opposite $\mathrm{dT}$ or $\mathrm{rU}$ more efficiently than replicative polymerases ${ }^{53,54}$. Translesion DNA polymerases harbor a larger binding pocket to accommodate lesions, however, not all can incorporate 2-OH-dATP. Pol $\eta$ incorporates 2-OH-dATP opposite all template bases except $\mathrm{dA}$, whereas Pol 1 cannot $^{55}$. Our data indicate that telomerase insertion of 2-OH-dATP more closely resembles other RTs compared to replicative and TLS polymerases, consistent with a similar binding pocket.

Similar to 2-OH-dATP, we found telomerase readily adds 6thio-dGTP to the telomeric end and exhibits very poor discrimination against 6-thio-dGTP. First, dGTP and 6-thio-dGTP yielded similar percent extension with all primers tested here. Second, although $t c$ TERT has lower affinity for 6-thio-dGTP, as indicated by a higher $K_{\mathrm{d}}$ than for dGTP, the polymerization rate was faster, yielding similar catalytic efficiencies. Third, 6-thiodGTP has a very low $\mathrm{IC}_{50}$ for telomerase repeat processivity inhibition. This is not surprising given that several human polymerases can insert 6-thio-dGTP with similar efficiencies as dGTP, and structures of Pol $\beta$ inserting 6-thio-dGTP opposite C, versus dGTP, are nearly identical ${ }^{56,57}$. However, while 6-thiodGTP can support DNA synthesis, it reduces primer elongation by DNA polymerases compared to $\mathrm{dGTP}^{56}$ and strongly inhibits telomerase processivity. While the sulfur substitution has a minor effect on catalysis, it has a dramatic effect on telomere elongation. Our results provide an explanation for why 6-thio-dG promotes telomere shortening in telomerase-positive cells, but not in telomerase-negative cells ${ }^{25}$.

We demonstrate that 2-OH-dATP and 6-thio-dGTP inhibit telomerase by disrupting the translocation step. While insertion of either modified dNTP did not block extension to the next template base, limited synthesis occurred after the first translocation for another repeat addition. Reactions with 6-thio-dGTP terminated immediately prior to, or right after, translocation. Translocation involves DNA:RNA duplex separation and repositioning of the DNA product to reveal the RNA template. Previous evidence suggests the DNA:RNA duplex separates and realigns outside the active site, then the repositioned hybrid binds in the active site ${ }^{48,58}$. Continuous strand separation is thought to maintain the hybrid at a consistent $5 \mathrm{bp}$ length, which is the optimal size for active site accomodation ${ }^{48}$. Protein interactions stabilize this very short hybrid, and telomerase affinity for the hybrid correlates with increased repeat processivity ${ }^{48}$. Therefore, perturbations to the $5 \mathrm{bp}$ hybrid, either via reduced melting temperature or protein interactions, could impact translocation. While substitution of a 6-thio-dG for dG moderately decreases DNA duplex thermal stability, the opening rate of a 6-thio-dG:dC base pair is 17 -fold faster than a $\mathrm{dG}: \mathrm{dC} \mathrm{bp}^{59}$. Structures indicate that the hydrogen bond is longer with the thio group and $\mathrm{dC}$, compared to with the carbonyl group, in the Pol $\beta$ active site ${ }^{57}$. Less is known about how 2-OH-dA impacts bp stability, however, alterations in the bp geometry with $\mathrm{rU}$ may impact the telomerase affinity for the RNA:DNA hybrid. Therefore, we proposed minor perturbations could significantly destabilize the already very short, thermally unstable $5 \mathrm{bp}$ RNA:DNA, and thereby disrupt translocation.

POT1-TPP1 results provide further evidence that 2-OH-dATP and 6-thio-dGTP disrupt translocation. POT1-TPP1 enhance telomerase repeat processivity by decreasing the primer dissociation rate and increasing translocation efficiency ${ }^{40}$. POT1-TPP1's ability to partially restore processivity in the presence of 2-OH-dATP, suggests that 2-OH-dA increases the rate of primer dissociation which is rescued partly by POT1-TPP1 increasing primer binding. However, POT1-TPP1 did not increase processivity in the presence of 6-thio-dGTP, suggesting that 6-thio-dG may be more destabilizing than $2-\mathrm{OH}-\mathrm{dA}$. When 6-thio-dGTP replaces dGTP, each telomeric repeat contains three 6-thio-dGs, whereas when 2-OH-dATP replaces dATP, each repeat contains one 2-OH-dA. Insertion of three modified dNTPs likely disrupts the DNA:RNA to such an extent that POT1-TPP1 enhancement of telomerase primer binding cannot compensate.

Since most tumors rely on telomerase to enable cellular immortality, one strategy to halt proliferation is to target telomerase with inhibitory nucleosides to prevent telomerase restoration of telomeres after each replication. NRTIs exploit the requirement of DNA polymerases and $\mathrm{RT}$ for a $3^{\prime} \mathrm{OH}$ on the ribose to catalyze addition of the incoming dNTP to the growing chain. While AZT-TP was shown to reduce telomerase products in vitro and cause telomere shortening in cells ${ }^{20,60,61}$, our studies provide the first direct evidence that NRTIs are telomerase chain terminators by showing that telomerase catalyzes addition of AZT-TP and ddITP to telomeric DNA. These results have important health implications since AZT has been pursued for anticancer therapy as a telomerase inhibitor ${ }^{60}$. Chronic AZT treatment in mice reduced tumor growth and promoted senescence and apoptosis in mammary carcinoma cells ${ }^{62}$. NRTI inhibition of telomerase has been proposed to promote cellular senescence and features of premature aging in HIV patients undergoing long-term treatments ${ }^{63}$. In addition, several recent preclinical studies showed that 6-thio-dG is an effective treatment for melanoma, lung cancer, and glioblastoma in murine models, and increases telomere dysfunction and shortening ${ }^{64-66}$. Here, we uncover the mechanism by which 6-thio-dGTP compromises telomere maintenance via disrupting telomerase translocation. Finally, the therapeutic dNTPs used in our study not only inhibit telomerase, but also inhibit mitochondrial DNA polymerase $\gamma$, leading to mitochondrial dysfunction and elevated ROS which damage dNTP pools ${ }^{26,27}$.Therefore, in conjunction with MTH1 inhibitors, our studies suggest therapeutic NRTIs or thiopurines may deliver a one-two punch to telomerase-driven cancers by inhibiting telomerase directly and indirectly through elevated oxidized dNTPs.

In summary, we show that both oxidized and therapeutic dNTPs inhibit telomerase activity by distinct mechanisms upon incorporation of either chain termination or disruption of telomerase translocation and subsequent repeat addition. Thus, our studies have important health implications for potential off target effects on long-term NRTI treatments, and for therapeutic strategies to target telomerase in cancer.

\section{Methods}

Telomerase preparation. Telomerase was immunopurified as described ${ }^{12}$ with some modification. HEK-293T (ATCC) cells were grown to $90 \%$ confluency in 
Dulbecco's modified Eagle's medium (Gibco) supplemented with 10\% FBS (Hyclone) and $1 \%$ penicillin-streptomycin (Corning) at $37^{\circ} \mathrm{C}$ and $5 \% \mathrm{CO}_{2}$. Cells were transfected with $10 \mu \mathrm{g}$ of pSUPER-hTR plasmid and $2.5 \mu \mathrm{g}$ of pVan107 hTERT plasmid diluted in $625 \mu \mathrm{l}$ of Opti-MEM (Gibco) mixed with $25 \mu \mathrm{l}$ of Lipofectamine 2000 (Thermo Fisher) diluted in $625 \mu \mathrm{l}$ of Opti-MEM. Cells expressing hTR and $3 \times$ FLAG-tagged human hTERT were harvested $48 \mathrm{~h}$ posttransfection, trypsinized, and washed with PBS, and then lysed in CHAPS buffer (10 mM Tris- $\mathrm{HCl}, 1 \mathrm{mM} \mathrm{MgCl} 2,1 \mathrm{mM}$ EDTA, 0.5\% CHAPS, $10 \%$ glycerol, $5 \mathrm{mM}$ $\beta$-mercaptoethanol, $120 \mathrm{U}$ RNasin Plus (Promega), $1 \mu \mathrm{g} \mathrm{ml}^{-1}$ each of pepstatin, aprotinin, leupeptin, and chymostatin, and $1 \mathrm{mM}$ AEBSF) for $30 \mathrm{~min}$ at $4^{\circ} \mathrm{C}$. Cell lysate supernatant was then flash frozen and stored at $-80^{\circ} \mathrm{C}$.

$80 \mu \mathrm{L}$ of anti-FLAG M2 bead slurry (Sigma Aldrich) (per T75 flask) was washed three times with 10 volumes of $1 \times$ human telomerase buffer $(50 \mathrm{mM}$ Tris- $\mathrm{HCl}, \mathrm{pH}$ $8,50 \mathrm{mM} \mathrm{KCl}, 1 \mathrm{mM} \mathrm{MgCl}_{2}, 1 \mathrm{mM}$ spermidine, and $5 \mathrm{mM} \beta$-mercaptoethanol) in $30 \%$ glycerol and harvested by centrifugation for $1 \mathrm{~min}$ at $3500 \mathrm{rpm}$ and $4{ }^{\circ} \mathrm{C}$. The bead slurry was added to the cell lysate and nutated for $4-6 \mathrm{~h}$ at $4^{\circ} \mathrm{C}$. The beads were harvested by $1 \mathrm{~min}$ centrifugation at $3500 \mathrm{rpm}$, and washed $3 \times$ with $1 \times$ human telomerase buffer with $30 \%$ glycerol. Telomerase was eluted from the beads with a $2 \times$ the bead volume of $250 \mu \mathrm{g} \mathrm{mL}^{-1} 3 \times \mathrm{FLAG}^{\circledast}$ peptide (Sigma Aldrich) in $1 \times$ telomerase buffer containing $150 \mathrm{mM} \mathrm{KCl}$. The bead slurry was nutated for $30 \mathrm{~min}$ at $4{ }^{\circ} \mathrm{C}$. The eluted telomerase was collected using Mini Bio-Spin ${ }^{\circledast}$ Chromatography columns (Bio-Rad). Samples were flash frozen and stored a $-80^{\circ} \mathrm{C}$.

Dot blot quantification of telomerase concentration. The concentration of telomerase pseudoknot RNA in the eluted telomerase preparation was measured as described ${ }^{58}$. Briefly, a serial dilution of in vitro transcribed pseudoknot region of hTR (Supplementary Fig. 1) was prepared as standards for quantification $(0.1,0.5$, $\left.1,5,10,50,100,250 \mathrm{fmol} \mu \mathrm{L}^{-1}\right)$. An aliquot of each standard and eluted telomerase $(10 \mu \mathrm{l})$ was added to $90 \mu \mathrm{l}$ of formamide buffer $(90 \%$ formamide, $1 \times$ tris-borate EDTA (TBE)). The samples were incubated at $70{ }^{\circ} \mathrm{C}$ for $10 \mathrm{~min}$ and then placed on ice. Positively charged Hybond $\mathrm{H}+$ membranes and Whatman filter papers (GE Healthcare Life Sciences) pre-incubated with $1 \times$ TBE were assembled onto the GE manifold dot blot apparatus and the samples were loaded onto the membrane via vacuum blotting. The membrane was air dried and then UV-crosslinked using a Stratagene Stratalinker 1800 with the Auto-Crosslink program. The membrane was prehybridized at $55^{\circ} \mathrm{C}$ in $25 \mathrm{ml}$ of Church buffer (1\% BSA, $1 \mathrm{mM}$ EDTA pH 7.5, $500 \mathrm{mM} \mathrm{Na} \mathrm{HPO}_{4} \mathrm{pH} 7.2,7 \%$ SDS) for $30 \mathrm{~min}$. A total of $1 \times 10^{6} \mathrm{CPM}$ of ${ }^{32} \mathrm{P}-$ labeled hTR oligonucleotide probe (Supplementary Table 1) was added to the hybridization buffer and incubated overnight at $55^{\circ} \mathrm{C}$. The membrane was washed $3 \times$ with $0.1 \times$ SSC, $0.1 \times$ SDS buffer. After vacuum sealing, the membrane was exposed to a phosphorimager screen for $1-3 \mathrm{~h}$ and imaged using a Typhoon scanner. ImageQuant TL 8.2 was used to quantify the blot intensities for the standard curve.

32P-end-labeling of DNA primers. 50 pmol of PAGE-purified DNA oligonucleotides (IDT) (Supplementary Table 1) were labeled with $\gamma^{32} \mathrm{P}$ ATP (Perkin Elmer) using T4 polynucleotide kinase (NEB) in $1 \times \mathrm{PNK}$ buffer $(70 \mathrm{mM}$ Tris- $\mathrm{HCl}$, $\mathrm{pH} 7.6,10 \mathrm{mM} \mathrm{MgCl}, 5 \mathrm{mM}$ DTT) in a $20 \mu$ reaction volume. The reaction was incubated for $1 \mathrm{~h}$ at $37^{\circ} \mathrm{C}$ followed by heat inactivation at $65^{\circ} \mathrm{C}$ for $20 \mathrm{~min}$. G-25 spin columns (GE Healthcare) were used to purify the end-labeled primer.

Telomerase activity assay with radiolabeled dNTPs. The telomerase assay was as described ${ }^{2}$. Reactions $(20 \mu \mathrm{l})$ contained $1 \times$ human telomerase buffer, $1 \mu \mathrm{M}$ oligonucleotide substrate, and dNTP mix as indicated in the figure legends. Reactions with cellular dNTP concentrations contained $24 \mu \mathrm{M}$ dATP, $29 \mu \mathrm{M}$ dCTP, $37 \mu \mathrm{M}$ dTTP, $5.2 \mu \mathrm{M}$ dGTP, and $0.3 \mu \mathrm{M} 3000 \mathrm{Ci}$ per mmol [a-32P] dGTP or $\left[\alpha^{32} \mathrm{P}\right]$ dTTP (PerkinElmer) as indicated. Reactions containing the modified dNTPs (Trilink Biotechnologies) substituted for their natural dNTP analog are indicated in the figure legends. The reactions were started by the addition of $3 \mu \mathrm{l}(\sim 35 \mathrm{fmol})$ of immunopurified telomerase eluent, incubated at $37^{\circ} \mathrm{C}$ for $1 \mathrm{~h}$, then terminated with $2 \mu \mathrm{l}$ of $0.5 \mathrm{mM}$ EDTA and heat inactivated at $65^{\circ} \mathrm{C}$ for $20 \mathrm{~min} .{ }^{32} \mathrm{P}$-end labeled 18-mer loading control $(8 \mathrm{fmol})$ was added to the terminated reactions before purification with an Illustra Microspin G-25 column (GE Healthcare). An equal volume of loading buffer ( $94 \%$ formamide, $0.1 \times$ TBE, $0.1 \%$ bromophenol blue, $0.1 \%$ xylene cyanol) was added to the reaction eluent from the G-25 spin column. The samples were heat denatured for $10 \mathrm{~min}$ at $100^{\circ} \mathrm{C}$ and loaded onto a $14 \%$ denaturing polyacrylamide gel $(7 \mathrm{M}$ urea, $1 \times \mathrm{TBE})$ and electrophoresed for 90 min at constant $38 \mathrm{~W}$. Samples were imaged using a Typhoon phosphorimager (GE Healthcare).

Telomerase activity assay with end-labeled primers. Reactions $(20 \mu \mathrm{l})$ contained $1 \times$ human telomerase buffer, $5 \mathrm{nM}$ of ${ }^{32} \mathrm{P}$-end-labeled primer and dNTPs as indicated in the figure legends. The reactions were started by the addition of $3 \mu \mathrm{l}$ of immunopurified telomerase eluent, incubated at $37^{\circ} \mathrm{C}$ for $1 \mathrm{~h}$, then terminated with $2 \mu \mathrm{l}$ of $0.5 \mathrm{mM}$ EDTA and heat inactivated at $65^{\circ} \mathrm{C}$ for $20 \mathrm{~min}$. An equal volume of loading buffer ( $94 \%$ formamide, $0.1 \times \mathrm{TBE}, 0.1 \%$ bromophenol blue, $0.1 \%$ xylene cyanol) was added to the reaction eluent. The samples were heat denatured for $10 \mathrm{~min}$ at $100^{\circ} \mathrm{C}$ and loaded onto a $14 \%$ denaturing acrylamide gel
(7 M urea, $1 \times \mathrm{TBE}$ ) and electrophoresed for $90 \mathrm{~min}$ at constant $38 \mathrm{~W}$. Samples were imaged using a Typhoon phosphorimager (GE Healthcare). Percent primer extension was calculated with ImageQuant TL 8.2 by measuring the intensity of each product band and dividing by the total radioactivity in the lane or total products, as indicated in the figure legends.

Quantitation. The processivity was calculated as described ${ }^{40,67}$. Repeat processivity from the direct telomerase extension assays was calculated as $R_{1 / 2}$ (equivalent to the half-time for decay in an exponential time course), which represents the median length of DNA product formed, expressed in terms of number of telomere repeats. First, the total volume counts for each product band extend by one or more telomere repeats were obtained using Image Quant TL. The volume counts were then normalized by dividing by the number of radiolabeled guanosines incorporated into the extended products based on the number of repeats added, termed corrected volume (corr vol). The "percent left behind" (\%LB) was calculated for each product band by summing the counts for that product band and for every product band below (shorter products), divided by the total counts for the lane, and then multiplied by 100 . The natural $\log$ of $(100-\% \mathrm{LB})$ was calculated and then plotted vs. repeat number for each product length. A linear regression line was fit to the data to determine the slope of the line. The $R_{1 / 2}$ value was calculated by dividing $-\ln (2)$ by the slope of each fitted line $\left(R_{1 / 2}=-\ln (2) /\right.$ slope $)$.

POT1/TPP1 purification. Full-length human POT1 was expressed as a SUMOstar-hexahistine-POT1 fusion protein in baculovirus-infected SF9 cells (Thermo Fisher Scientific), as described ${ }^{68}$. Sf9 insect cells expressing recombinant POT1 were lysed in buffer ( $25 \mathrm{mM}$ Tris pH 8.0, $500 \mathrm{mM} \mathrm{NaCl}, 10 \mathrm{mM}$ imidazole $)$ with a protease inhibitor cocktail (Roche Molecular Biochemicals). Subsequent buffers contained protease inhibitors $2 \mu \mathrm{g} \mathrm{ml}^{-1}$ each of aprotinin, leupeptin, chymostatin, and pepstatin, $1 \mathrm{mM}$ AEBSF and $5 \mathrm{mM} \beta$-mercaptoethanol. Following sonication, the lysate was centrifuged at 40,000 r.p.m. for $75 \mathrm{~min}$ at $4{ }^{\circ} \mathrm{C}$. The supernatant was filtered through a 0.2 micron filter and loaded onto a HisTrap FF column (GE LifeSciences), followed by washing and elution with 20 and $200 \mathrm{mM}$ imidazole, respectively, using an ATKA Pure FPLC (GE Healthcare). Fractions containing POT1 were pooled and incubated with SUMOstar protease (Ulp1 variant, LifeSensors) for one hour with gentle mixing by rotation $20 \mathrm{rpm}$ at room temperature to cleave the histidine tag. POT1 was separated from the protease and cleaved tag by size-exclusion FPLC chromatography. Samples were loaded on a HiLoad 16/600 Superdex 200 column (GE Healthcare) equilibrated with $25 \mathrm{mM}$ Tris $\mathrm{pH} 8.0,150 \mathrm{mM} \mathrm{NaCl}, 5 \mathrm{mM}$ DTT, and protease inhibitors. Eluted fractions containing POT1 were collected and pooled. Purified TPP1-N (amino acids 89-334) protein was obtained from soluble lysates of isopropyl $\beta$-D-thiogalactopyranoside-induced BL21(DE3) pLysS cells (Promega) after nickel agarose chromatography, treatment with Ulp1 protease to cleave the Smt 3 tag31 and sizeexclusion chromatography as described ${ }^{69}$. Expression was induced with $0.8 \mathrm{mM}$ IPTG in cells for about $13 \mathrm{~h}$ at $24^{\circ} \mathrm{C}$, and then harvested by centrifugation at 4500 $\mathrm{rpm}$ for $20 \mathrm{~min}$. Cell pellets were lysed in buffer $(20 \mathrm{mM}$ Tris pH 7.5, $500 \mathrm{mM}$ $\mathrm{NaCl}, 10 \mathrm{mM}$ imidazole) with a protease inhibitor cocktail (Roche Molecular Biochemicals). Following sonication, the lysate was centrifuged $40,000 \mathrm{rpm}$ for 75 $\min$ at $4{ }^{\circ} \mathrm{C}$. The supernatant was filtered through a 0.2 micron filter and loaded onto a HisTrap FF column (GE LifeSciences), followed by washing and elution with 20 and $200 \mathrm{mM}$ imidazole, respectively, using an ATKA Pure FPLC (GE Healthcare). Fractions containing TPP1 were concentrated and exchanged into buffer ( 25 $\mathrm{mM}$ Tris pH 8.0, $150 \mathrm{mM} \mathrm{NaCl}, 5 \mathrm{mM}$ DTT) using a Centricon-10 device (Amicon). The sample was incubated with SUMO (Ulp1) protease (Invitrogen) overnight at $4{ }^{\circ} \mathrm{C}$ with gentle mixing by rotation at $20 \mathrm{rpm}$ to cleave the tag. Samples were then loaded on a HiLoad 16/600 Superdex 200 column (GE Healthcare). Eluted fractions containing TPP1 were collected and pooled. Protein concentration was determined by Bradford Assay (BioRad) and purity was determined by SDS-PAGE and Coomassie staining.

Expression and purification of tcTERT. tcTERT was expressed and purified as described with some modifications ${ }^{42,43}$. An Epiphyte3 LEX bioreactor was used to grow $t c$ TERT in BL-21(DE3) pLysS cells at $37^{\circ} \mathrm{C}$ until they reached an $\mathrm{OD}_{600}$ of $0.6-0.8$, after which protein expression was induced with $1 \mathrm{mM}$ isopropyl $\beta$-D-1thiogalactopyranoside (IPTG) and the temperature was decreased to $30^{\circ} \mathrm{C}$ for $4-5$ hours of protein induction. Cells were harvested via centrifugation at $4000 \times g$ until lysis. For $t c$ TERT purification, buffers containing $0.75 \mathrm{M} \mathrm{KCl}$ and $10 \%$ glycerol was used for the initial purification step on Ni-NTA columns (GE Healthcare). Samples were further purified via cation exchange on a POROS HS column (Thermo Fisher), using a salt gradient of $0.5 \mathrm{M} \mathrm{KCl}$ to $1.5 \mathrm{M} \mathrm{KCl}$. Next, the hexahistidine tag was cleaved with Tobacco etch virus (TEV) protease overnight at $4{ }^{\circ} \mathrm{C}$. The cut tag and TEV protease were separated from the protein with an additional Ni-NTA column chromatography step. The final chromatography step was a Sephacryl S200 16/60, GE Healthcare column using a buffer containing $50 \mathrm{mM}$ Tris-HCl, $\mathrm{pH}$ 7.5, $10 \%$ glycerol, $0.8 \mathrm{M} \mathrm{KCl}$, and $1 \mathrm{mM}$ Tris(2-carboxyethyl)phosphine (TCEP). Resultant $t c$ TERT was concentrated down to $18 \mathrm{mg} \mathrm{ml}^{-1}$ and stored at $4{ }^{\circ} \mathrm{C}^{42}$.

Pre-steady-state kinetics of tcTERT inserting 6-thio-dGTP. Pre-steady-state kinetic parameters of $t c$ TERT were obtained using established pre-steady-state 
kinetics protocols for DNA polymerases, also known as single turnover kinetics $^{70,71}$. Briefly, we preincubated $2 \mu \mathrm{M} t c$ TERT with $200 \mathrm{nM}$ annealed DNA: RNA hybrid substrate, with a 6-FAM label on the $5^{\prime}$ end of the DNA component. We then used a KinTek RQF-3 (a rapid quench-flow instrument) to mix equal ratios of the incoming nucleotide triphosphate and $10 \mathrm{mM} \mathrm{MgCl}_{2}$ with the existing mix of $t c$ TERT and its DNA:RNA hybrid substrate. Reactions were run at $37^{\circ} \mathrm{C}$ and quenched at various timepoints with $100 \mathrm{mM}$ EDTA $\mathrm{pH}$ 7.5. In each case, the conditions used for each reaction were: $25 \mathrm{mM}$ Tris $\mathrm{pH} 7.5,0.05 \mathrm{mg} \mathrm{ml}^{-1}$ bovine serum albumin, $1 \mathrm{mM}$ dithiothreitol, $10 \%$ glycerol, $200 \mathrm{mM} \mathrm{KCl}, 1 \mu \mathrm{M} t c$ TERT, $100 \mathrm{nM}$ annealed DNA:RNA hybrid substrate, and varying concentrations of 6thio-dGTP. After each reaction, the samples were transferred to a DNA gel loading buffer, containing $100 \mathrm{mM}$ EDTA, $80 \%$ deionized formamide, $0.25 \mathrm{mg} \mathrm{ml}^{-1}$ bromophenol blue, and $0.25 \mathrm{mg} \mathrm{ml}^{-1}$ xylene cyanol. These mixes were then incubated at $95^{\circ} \mathrm{C}$ for $5 \mathrm{~min}$, and loaded onto a $21 \%$ denaturing polyacrylamide gel. These gels were run at $700 \mathrm{~V}, 60 \mathrm{~A}$, and $30 \mathrm{~W}$ at $30^{\circ} \mathrm{C}$ in order to separate the reaction product from its substrate.

Gels were scanned and imaged using a GE Typhoon FLA 9500 imager, and the ratios of product to substrate were quantified using ImageJ version $1.52 \mathrm{k}^{72}$. Means and standard deviations from at least three independent replicates were calculated, and graphed using KaleidaGraph version 4.5.2. Plots of product formation over time were fit to the exponential equation (1) to determine $k_{\text {obs }}$ values:

$$
[P]=A\left(1-\mathrm{e}^{-k_{\mathrm{obs}} t}\right) \text {. }
$$

In which $[P]$ is the concentration of the product, $A$ is the target engagement (amplitude), and $t$ is the reaction time. After $k_{\text {obs }}$ values were determined for multiple nucleotide triphosphate concentrations, the data was replot to compare $k_{\text {obs }}$ to concentration of nucleotide triphosphate, and fit to Eq. (2):

$$
k_{\mathrm{obs}}=\frac{k_{\mathrm{pol}}[\mathrm{NTP}]}{K_{\mathrm{d}}+[\mathrm{NTP}]} .
$$

with $k_{\text {pol }}$ representing the theoretical maximum value of $k_{\text {obs }}$, and [NTP] representing the concentration of the nucleotide of interest.

Polymerase $\boldsymbol{\beta}$ dGTP run-on assay. $40 \mathrm{nM}$ polymerase $\beta, 400 \mathrm{nM}$ primer-template DNA with a $5^{\prime}$ 6-FAM-labeled PolB Primer 1 annealed to PolB Primer 2 (Supplementary Table 1), were preincubated for $20 \mathrm{~min}$. We then used a multi-channel pipette to mix equal ratios of the incoming nucleotide with $1 \mathrm{mM} \mathrm{MgCl}_{2}$ to start the reaction. Reactions were run at $37^{\circ} \mathrm{C}$ in a LabDoctor ${ }^{\mathrm{mu}}$ heating and quenching was accomplished using a solution of DNA gel-loading buffer. In each reaction the conditions were: $50 \mathrm{mM}$ Tris $\mathrm{pH} 7.5,0.1 \mathrm{mg} \mathrm{ml}^{-1}$ bovine serum albumin, $1 \mathrm{mM}$ dithiothreitol, $10 \%$ glycerol, $100 \mathrm{mM} \mathrm{KCl}, 20 \mathrm{nM}$ polymerase $\beta, 200 \mathrm{nM}$ primer template DNA, and either 50 or $200 \mu \mathrm{M}$ dGTP or dTTP. These mixes were then incubated at $95^{\circ} \mathrm{C}$ for $5 \mathrm{~min}$, and loaded onto a $21 \%$ denaturing polyacrylamide gel. These gels were run at $700 \mathrm{~V}, 60 \mathrm{~A}$, and $30 \mathrm{~W}$ at $30^{\circ} \mathrm{C}$ in order to separate the reaction product from its substrate. Gels were scanned and imaged using a GE Typhoon FLA 9500 imager.

Statistics. Means and standard deviations were calculated using Graph Pad Prism version 8 .

Reporting summary. Further information on research design is available in the Nature Research Reporting Summary linked to this article.

\section{Data availability}

Supplementary Information including uncropped images are included in the online version of this manuscript. All data supporting the findings of this study are available from the corresponding author upon reasonable request. Source data are provided with this paper.

Received: 21 February 2020; Accepted: 28 September 2020;

Published online: 20 October 2020

\section{References}

1. de Lange, T. Shelterin-mediated telomere protection. Annu. Rev. Genet. 52, 223-247 (2018).

2. Armanios, M. \& Blackburn, E. H. The telomere syndromes. Nat. Rev. Genet. 13, 693-704 (2012).

3. Levy, M. Z., Allsopp, R. C., Futcher, A. B., Greider, C. W. \& Harley, C. B. Telomere end-replication problem and cell aging. J. Mol. Biol. 225, 951-960 (1992).

4. Greider, C. W. \& Blackburn, E. H. A telomeric sequence in the RNA of Tetrahymena telomerase required for telomere repeat synthesis. Nature 337, 331-337 (1989).
5. Wu, R. A., Upton, H. E., Vogan, J. M. \& Collins, K. Telomerase mechanism of telomere synthesis. Annu. Rev. Biochem. 86, 439-460 (2017).

6. Hockemeyer, D. \& Collins, K. Control of telomerase action at human telomeres. Nat. Struct. Mol. Biol. 22, 848-852 (2015).

7. Kim, N. W. et al. Specific association of human telomerase activity with immortal cells and cancer. Science 266, 2011-2015 (1994).

8. Barnes, R. P., Fouquerel, E. \& Opresko, P. L. The impact of oxidative DNA damage and stress on telomere homeostasis. Mech. Ageing Dev. 177, 37-45 (2019).

9. Tsuzuki, T. et al. Spontaneous tumorigenesis in mice defective in the MTH1 gene encoding 8-oxo-dGTPase. Proc. Natl Acad. Sci. USA 98, 11456-11461 (2001).

10. Gad, H. et al. MTH1 inhibition eradicates cancer by preventing sanitation of the dNTP pool. Nature 508, 215-221 (2014).

11. Rai, P. \& Sobol, R. W. Mechanisms of MTH1 inhibition-induced DNA strand breaks: The slippery slope from the oxidized nucleotide pool to genotoxic damage. DNA Repair 77, 18-26 (2019).

12. Fouquerel, E. et al. Oxidative guanine base damage regulates human telomerase activity. Nat. Struct. Mol. Biol. 23, 1092-1100 (2016).

13. Aeby, E., Ahmed, W., Redon, S., Simanis, V. \& Lingner, J. Peroxiredoxin 1 protects telomeres from oxidative damage and preserves telomeric DNA for extension by telomerase. Cell Rep. 17, 3107-3114 (2016).

14. Ahmed, W. \& Lingner, J. PRDX1 and MTH1 cooperate to prevent ROSmediated inhibition of telomerase. Genes Dev. 32, 658-669 (2018).

15. Holec, A. D., Mandal, S., Prathipati, P. K. \& Destache, C. J. Nucleotide reverse transcriptase inhibitors: a thorough review, present status and future perspective as HIV therapeutics. Curr. HIV Res. 15, 411-421 (2017).

16. Engelman, A. \& Cherepanov, P. The structural biology of HIV-1: mechanistic and therapeutic insights. Nat. Rev. Microbiol. 10, 279-290 (2012).

17. Smith, R. L., de Boer, R., Brul, S., Budovskaya, Y. \& van Spek, H. Premature and accelerated aging: HIV or HAART? Front. Genet. 3, 328 (2012).

18. Cohen, J. \& Torres, C. HIV-associated cellular senescence: a contributor to accelerated aging. Ageing Res. Rev. 36, 117-124 (2017).

19. Strahl, C. \& Blackburn, E. H. The effects of nucleoside analogs on telomerase and telomeres in Tetrahymena. Nucleic Acids Res. 22, 893-900 (1994).

20. Strahl, C. \& Blackburn, E. H. Effects of reverse transcriptase inhibitors on telomere length and telomerase activity in two immortalized human cell lines. Mol. Cell. Biol. 16, 53-65 (1996).

21. Hukezalie, K. R., Thumati, N. R., Cote, H. C. \& Wong, J. M. In vitro and ex vivo inhibition of human telomerase by anti-HIV nucleoside reverse transcriptase inhibitors (NRTIs) but not by non-NRTIs. PLoS ONE 7, e47505 (2012).

22. Schmiegelow, K., Nielsen, S. N., Frandsen, T. L. \& Nersting, J. Mercaptopurine/methotrexate maintenance therapy of childhood acute lymphoblastic leukemia: clinical facts and fiction. J. Pediatr. Hematol. Oncol. 36, 503-517 (2014).

23. Bradford, K. \& Shih, D. Q. Optimizing 6-mercaptopurine and azathioprine therapy in the management of inflammatory bowel disease. World J. Gastroenterol. 17, 4166-4173 (2011).

24. Zhang, G. \& Shay, J. W. Inducing rapid telomere irreparable damage in telomerase-expressing cancers. Oncotarget 9, 35803-35804 (2018).

25. Mender, I., Gryaznov, S., Dikmen, Z. G., Wright, W. E. \& Shay, J. W. Induction of telomere dysfunction mediated by the telomerase substrate precursor 6-thio-2'-deoxyguanosine. Cancer Discov. 5, 82-95 (2015).

26. Lewis, W., Day, B. J. \& Copeland, W. C. Mitochondrial toxicity of NRTI antiviral drugs: an integrated cellular perspective. Nat. Rev. Drug Discov. 2, 812-822 (2003).

27. Daehn, I., Brem, R., Barkauskaite, E. \& Karran, P. 6-Thioguanine damages mitochondrial DNA and causes mitochondrial dysfunction in human cells FEBS Lett. 585, 3941-3946 (2011).

28. Gomez, D. E., Armando, R. G. \& Alonso, D. F. AZT as a telomerase inhibitor. Front. Oncol. 2, 113 (2012).

29. Cristofari, G. \& Lingner, J. Telomere length homeostasis requires that telomerase levels are limiting. EMBO J. 25, 565-574 (2006).

30. Xi, L. \& Cech, T. R. Inventory of telomerase components in human cells reveals multiple subpopulations of hTR and hTERT. Nucleic Acids Res. 42, 8565-8577 (2014)

31. Cristofari, G. et al. Low- to high-throughput analysis of telomerase modulators with Telospot. Nat. Methods 4, 851-853 (2007).

32. Traut, T. W. Physiological concentrations of purines and pyrimidines. Mol. Cell. Biochem. 140, 1-22 (1994).

33. Wang, F. et al. The POT1-TPP1 telomere complex is a telomerase processivity factor. Nature 445, 506-510 (2007).

34. Ahluwalia, G. et al. Initial studies on the cellular pharmacology of $2^{\prime}, 3^{\prime}$ dideoxyinosine, an inhibitor of HIV infectivity. Biochem. Pharm. 36, 3797-3800 (1987) 
35. Johnson, M. A. \& Fridland, A. Phosphorylation of $2^{\prime}, 3^{\prime}$-dideoxyinosine by cytosolic 5'-nucleotidase of human lymphoid cells. Mol. Pharm. 36, 291-295 (1989).

36. Hsu, G. W., Ober, M., Carell, T. \& Beese, L. S. Error-prone replication of oxidatively damaged DNA by a high-fidelity DNA polymerase. Nature 431, 217-221 (2004).

37. Tomlinson, C. G. et al. Two-step mechanism involving active-site conformational changes regulates human telomerase DNA binding. Biochem. J. 465, 347-357 (2015).

38. Loayza, D., Parsons, H., Donigian, J., Hoke, K. \& de Lange, T. DNA binding features of human POT1: a nonamer $5^{\prime}$-TAGGGTTAG-3' minimal binding site, sequence specificity, and internal binding to multimeric sites. J. Biol. Chem. 279, 13241-13248 (2004).

39. Zaug, A. J., Podell, E. R., Nandakumar, J. \& Cech, T. R. Functional interaction between telomere protein TPP1 and telomerase. Genes Dev. 24, 613-622 (2010).

40. Latrick, C. M. \& Cech, T. R. POT1-TPP1 enhances telomerase processivity by slowing primer dissociation and aiding translocation. EMBO J. 29, 924-933 (2010).

41. Kaul, Z., Cesare, A. J., Huschtscha, L. I., Neumann, A. A. \& Reddel, R. R. Five dysfunctional telomeres predict onset of senescence in human cells. EMBO Rep. 13, 52-59 (2011).

42. Gillis, A. J., Schuller, A. P. \& Skordalakes, E. Structure of the Tribolium castaneum telomerase catalytic subunit TERT. Nature 455, 633-637 (2008)

43. Schaich, M. A. et al. Mechanisms of nucleotide selection by telomerase. Elife 9, e55439 (2020).

44. Bertram, J. G., Oertell, K., Petruska, J. \& Goodman, M. F. DNA polymerase fidelity: comparing direct competition of right and wrong dNTP substrates with steady state and pre-steady state kinetics. Biochemistry 49, 20-28 (2010).

45. Collins, K. Ciliate telomerase biochemistry. Annu. Rev. Biochem. 68, 187-218 (1999).

46. Chen, Y., Podlevsky, J. D., Logeswaran, D. \& Chen, J. J. A single nucleotide incorporation step limits human telomerase repeat addition activity. EMBO J. 37, e97953 (2018).

47. Hardy, C. D., Schultz, C. S. \& Collins, K. Requirements for the dGTPdependent repeat addition processivity of recombinant Tetrahymena telomerase. J. Biol. Chem. 276, 4863-4871 (2001).

48. Qi, X. et al. RNA/DNA hybrid binding affinity determines telomerase template-translocation efficiency. EMBO J. 31, 150-161 (2012).

49. Koag, M. C., Jung, H. \& Lee, S. Mutagenic replication of the major oxidative adenine lesion 7,8-dihydro-8-oxoadenine by human DNA polymerases. J. Am. Chem. Soc. 141, 4584-4596 (2019).

50. Hernandez-Sanchez, W. et al. A non-natural nucleotide uses a specific pocket to selectively inhibit telomerase activity. PLoS Biol. 17, e3000204 (2019).

51. Maciejewska, A. M., Lichota, K. D. \& Kusmierek, J. T. Neighbouring bases in template influence base-pairing of isoguanine. Biochem. J. 369, 611-618 (2003).

52. Robinson, H. et al. $2^{\prime}$-Deoxyisoguanosine adopts more than one tautomer to form base pairs with thymidine observed by high-resolution crystal structure analysis. Biochemistry 37, 10897-10905 (1998).

53. Kamiya, H. \& Kasai, H. Formation of 2-hydroxydeoxyadenosine triphosphate, an oxidatively damaged nucleotide, and its incorporation by DNA polymerases. Steady-state kinetics of the incorporation. J. Biol. Chem. 270, 19446-19450 (1995)

54. Bukowska, A. M. \& Kusmierek, J. T. Miscoding properties of isoguanine (2oxoadenine) studied in an AMV reverse transcriptase in vitro system. Acta Biochim. Pol. 43, 247-254 (1996).

55. Hidaka, K. et al. Specificity of mutations induced by incorporation of oxidized dNTPs into DNA by human DNA polymerase eta. DNA Repair 7, 497-506 (2008).

56. Ling, Y. H., Nelson, J. A., Cheng, Y. C., Anderson, R. S. \& Beattie, K. L. $2^{\prime}$ Deoxy-6-thioguanosine $5^{\prime}$-triphosphate as a substrate for purified human DNA polymerases and calf thymus terminal deoxynucleotidyltransferase in vitro. Mol. Pharm. 40, 508-514 (1991)

57. Schaich, M. A., Smith, M. R., Cloud, A. S., Holloran, S. M. \& Freudenthal, B. D. Structures of a DNA polymerase inserting therapeutic nucleotide analogues. Chem. Res. Toxicol. 30, 1993-2001 (2017).

58. Parks, J. W. \& Stone, M. D. Coordinated DNA dynamics during the human telomerase catalytic cycle. Nat. Commun. 5, 4146 (2014).

59. Bohon, J. \& de los Santos, C. R. Effect of 6-thioguanine on the stability of duplex DNA. Nucleic Acids Res. 33, 2880-2886 (2005).

60. Gomez, D., Kassim, A. \& Olivero, O. Preferential incorporation of $3^{\prime}$-azido$2^{\prime}, 3^{\prime}$-dideoxythymidine (azt) in telomeric sequences of cho cells. Int. J. Oncol. 7, 1057-1060 (1995).

61. Olivero, O. A. \& Poirier, M. C. Preferential incorporation of $3^{\prime}$-azido- $2^{\prime}, 3^{\prime}$ dideoxythymidine into telomeric DNA and Z-DNA-containing regions of Chinese hamster ovary cells. Mol. Carcinog. 8, 81-88 (1993).

62. Tejera, A. M., Alonso, D. F., Gomez, D. E. \& Olivero, O. A. Chronic in vitro exposure to $3^{\prime}$-azido- $2^{\prime}, 3^{\prime}$-dideoxythymidine induces senescence and apoptosis and reduces tumorigenicity of metastatic mouse mammary tumor cells. Breast Cancer Res. Treat. 65, 93-99 (2001).

63. Torres, R. A. \& Lewis, W. Aging and HIV/AIDS: pathogenetic role of therapeutic side effects. Lab. Investig. 94, 120-128 (2014).

64. Zhang, G. et al. Induction of telomere dysfunction prolongs disease control of therapy-resistant melanoma. Clin. Cancer Res. 24, 4771-4784 (2018).

65. Sengupta, S. et al. Induced telomere damage to treat telomerase expressing therapy-resistant pediatric brain tumors. Mol. Cancer Ther. 17, 1504-1514 (2018).

66. Mender, I. et al. Telomerase-mediated strategy for overcoming non-small cell lung cancer targeted therapy and chemotherapy resistance. Neoplasia $\mathbf{2 0}$ 826-837 (2018).

67. Wang, F. \& Lei, M. Human telomere POT1-TPP1 complex and its role in telomerase activity regulation. Methods Mol. Biol. 735, 173-187 (2011).

68. Kocak, H. et al. Hoyeraal-Hreidarsson syndrome caused by a germline mutation in the TEL patch of the telomere protein TPP1. Genes Dev. 28, 2090-2102 (2014)

69. Hwang, H., Buncher, N., Opresko, P. L. \& Myong, S. POT1-TPP1 regulates telomeric overhang structural dynamics. Structure 20, 1872-1880 (2012).

70. Powers, K. T. \& Washington, M. T. Analyzing the catalytic activities and interactions of eukaryotic translesion synthesis polymerases. Methods Enzymol. 592, 329-356 (2017).

71. Beard, W. A. et al. Polymerase beta activation. J. Biol. Chem. 289, 31411-31422 (2014).

72. Schneider, C. A., Rasband, W. S. \& Eliceiri, K. W. NIH Image to ImageJ: 25 years of image analysis. Nat. Methods 9, 671-675 (2012).

\section{Acknowledgements}

We thank Dr. Thomas Cech and Arthur Zaug (University of Colorado) for pSUPER-hTR and pVan107 hTERT-FLAG plasmids. We thank Dr. Michael Stone (UC Santa Cruz) for reagents and assistance with the RNA dot blots. We thank Dr. Jayakrishnan Nandakumar (University of Michigan) for the SUMOstar-hexahistine-POT1 baculovirus and Dr. Ming Lei (Sanghai Jiao Tong University) for the TPP1-N expression construct. This work was supported by NIH grants R01CA207342, R35030396 (to P.L.O.) and R35-GM128562 (to B.D.F. and G.A.W.). This project was supported in part by award P30CA047904.

\section{Author contributions}

S.L.S. performed telomerase isolation assay, S.L.S. and G.A.W. performed biochemical experiments. S.L.S., G.A.W., B.D.F., and P.L.O. designed experiments, analyzed the data and wrote the manuscript.

\section{Competing interests}

The authors declare no competing interests.

\section{Additional information}

Supplementary information is available for this paper at https://doi.org/10.1038/s41467020-19115-y.

Correspondence and requests for materials should be addressed to P.L.O.

Peer review information Nature Communications thanks Dirk Hockemeyer and the other, anonymous, reviewer(s) for their contribution to the peer review of this work

Reprints and permission information is available at http://www.nature.com/reprints

Publisher's note Springer Nature remains neutral with regard to jurisdictional claims in published maps and institutional affiliations.

Open Access This article is licensed under a Creative Commons Attribution 4.0 International License, which permits use, sharing, adaptation, distribution and reproduction in any medium or format, as long as you give appropriate credit to the original author(s) and the source, provide a link to the Creative Commons license, and indicate if changes were made. The images or other third party material in this article are included in the article's Creative Commons license, unless indicated otherwise in a credit line to the material. If material is not included in the article's Creative Commons license and your intended use is not permitted by statutory regulation or exceeds the permitted use, you will need to obtain permission directly from the copyright holder. To view a copy of this license, visit http://creativecommons.org/ licenses/by/4.0/

(c) The Author(s) 2020 